Western University Scholarship@Western

1991

\title{
Perfect Equilibria in a Negotiation Model
}

Lutz-Alexander Busch

Quan Wen

Follow this and additional works at: https://ir.lib.uwo.ca/economicsresrpt

Part of the Economics Commons

Citation of this paper:

Busch, Lutz-Alexander, Quan Wen. "Perfect Equilibria in a Negotiation Model." Department of Economics Research Reports, 9108. London, ON: Department of Economics, University of Western Ontario (1991). 
ISSN : $0318-725 \mathrm{X}$

ISBN : $0-7714-1.32 .3-8$

\author{
RESEARCH REPORT 9108 \\ PERFECT EQUILIBRIA IN A \\ NEGOTIATION MODEL \\ b. \\ Lutz-Alexander Busch \\ and \\ Quan Wen
}

September 1991

Department of Economics

Soclal Science Centre

University of Western Ontario

London. Ontario. Canada

N6A $5 \mathrm{C2}$

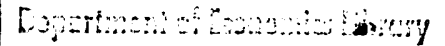

SEP 181991

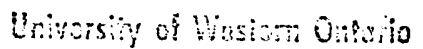




\title{
Perfect Equilibria in a Negotiation Model
}

\author{
Lutz-Alexander Busch \\ Dept. of Economics \\ University of Western Ontario \\ London, Ontario \\ N6A 5C2 \\ and $^{1}$ \\ Quan Wen \\ Dept. of Economics \\ University of Windsor \\ Windsor, Ontario \\ N9B 3P4
}

\section{June 1991}

Please direct all correspondence concerning this paper to Quan Wen.

\footnotetext{
${ }^{1}$ This paper is a revised version of part of our theses. We wish to thank our supervisors Ignatius Horstmann and Phil Reny for their comments, patience and encouragement. Valuable comments were also received from Arthur Robson, Abhijit Sengupta, Al Slivinski and participants in the Theory Workshop at the University of Western Ontario.
} 


\begin{abstract}
In standard bargaining models the disagreement payoff is exogenous and history independent. Here a model of negotiations is proposed which makes the disagreement payoff in every period the outcome of a normal form stage game. The model thereby allows for an analysis of the role played by strategic behaviour during periods in which no agreement has been achieved, especially as this behaviour relates to the form of the negotiated outcome. The paper characterizes players' worst equilibrium payoffs in terms of the structure of payoffs in the stage game. The set of subgame perfect equilibria of the model is characterized in terms of these worst equilibrium payoffs. Quite generally, many feasible outcomes of the negotiation game can be sustained as subgame perfect equilibria. In particular, many Pareto inefficient outcomes are sustainable even in the presence of complete information and full rationality.
\end{abstract}

Keywords: bargaining, negotiation, repeated games 


\section{Introduction}

Nine years after its publication, Rubinstein's bargaining model (Rubinstein (1982)) is well understood and extensively used in modelling the allocation of gains from trade. It is an attractive and simple model of dynamic allocation, not only due to its clear structure and easy solution, but also due to its unique subgame perfect equilibrium, which features immediate agreement. This latter feature, on the other hand, has been perceived as one of the limitations of the bargaining model, since many circumstances in which bargaining is thought to occur feature delay.

While many writers have analysed the contribution imperfect information can have in introducing delay into the bargaining model, ${ }^{2}$ and recently the fact that delay and strike are not synonymous has been pointed out, ${ }^{3}$ a fundamental question about the bargaining model remains and has sofar not been addressed: How well does the Rubinstein model treat the time aspect of negotiations?

Reference is made here to the fact that time enters the bargaining model only via the discount factor, making delay in reaching agreement costly. This assumption effectively isolates the pure bargaining aspect of a situation. In particular, the bargaining model assumes that there are no intratemporal actions or payoffs. ${ }^{4}$ This implies that only the additional payoffs from agreement matter to the parties and their payoffs during bargaining are irrelevant. While this may be a reasonable approximation for many situations, and precisely captures the spirit of the bargaining problem as defined by Rubinstein (1982, p.97), this aspect of the bargaining model limits the set of situations which map into the model.

\footnotetext{
${ }^{2}$ Wilson (1987) has a survey of related literature. See also the discussion section for some references.

${ }^{3}$ Haller and Holden (1990) and Fernandez and Glazer (1991) both have a model in which the decision to strike in a period of delay is modelled explicitly.

${ }^{4}$ There may be payoffs, but they are assumed constant and exogenous, which allows for them to be normalized to zero.
} 
Consider, for example, some typical instances of negotiations, such as peace- , wage- or trade negotiations. One characteristic of these is that they take time - not in the sense of time before agreement, or delay, but in the sense that real time elapses between offers and counter-offers. The parties involved in the negotiations have an ongoing relationship which is not placed on hold while they negotiate, but instead requires decisions to be made and yields payoffs concurrently with the parties' efforts to reach agreement. This relationship may not be part of the negotiations per se, but is coincidentally linked to the negotiation process due to the fact that it affects the parties' status quo point. The bargaining model fails to capture this aspect.

Rubinstein's bargaining solution depends critically on the relationship between status quo point and bargaining frontier, and both are assumed stationary and exogenous in his model. While it can be shown that the bargaining model can be easily extended to deal with more general exogenous bargaining frontiers (Binmore (1987)), and exogenous nonstationary staius quo points (Lemma, Section 3.2 below), exogeneity is critical. This limits the model to instances of simple negotiations where offers are quick and not much is going on between offers - such as splitting a pie or an inheritance.

The current paper presents a model in which the status quo point of negotiations is fully endogenized. This is achieved by allowing the parties to make alternating offers as in bargaining, but to allow them to play a normal form game, which determines their disagreement period payoffs, after an offer has been rejected. Thus it is possible to account for the importance attached to the agreement sought via the negotiations as well as the strategic behaviour and payoffs during the negotiations. ${ }^{5}$

In what follows, the players' optimal punishment payoffs are derived and implemented

\footnotetext{
${ }^{5}$ Note that, while addressing the repeated game aspect of the disagreement payoff determination, the theory of repeated games alone cannot accommodate the situations under consideration due to the fact that a fixed time horizon is assumed - contradicting the inherent endogeneity of the duration of negotiations. A merger of bargaining and repeated game ideas is thus required.
} 
as subgame perfect equilibria (SPE). These worst equilibrium payoffs are shown to be characterizable in terms of the payoff structure of the repeated game played before agreement is reached. Finally, all SPE payoffs of the negotiation model are characterized by showing that for a 'large enough' discount factor any game payoffs above the punishment payoffs can be supported by SPE strategies. ${ }^{6}$

The paper is structured as follows: Section 2 describes the model and defines all necessary concepts. Section 3 states the results of the paper while also presenting some examples. A discussion of the model's contribution to some of the issues raised in the literature on bargaining as well as some concluding remarks can be found in section 4 . All proofs are in an appendix.

\section{The Model}

Define a Negotiation Problem as a situation where two rational parties have a surplus available to them if and only if they can agree on an allocation of it, while simultaneously being involved in an ongoing repeated relationship. The questions asked about the negotiation problem are i) what agreements are possible in equilibrium, ii) how long it will take to reach agreement, and $i i i$ ) what the equilibrium value of such a relationship will be to the parties, taking into account that not only the agreement but also the way it is achieved yields payoffs.

Consider, for example, the following situation: There are two of possibly many Cournot firms in a market. Both face a relatively large fixed cost. Assuming that no side-payments are possible but the merger into a single firm is allowed, they could both gain by forming a monopoly with only one plant. Negotiations are held over the allocation of the resulting

\footnotetext{
${ }^{6}$ Considerable intellectual debt is owed to the repeated game literature, in terms of terminology as well as approach. In fact, the model can be applied to the question of repeated 2-player games with an endogenous time horizon. See also the discussion and footnote 12.
} 


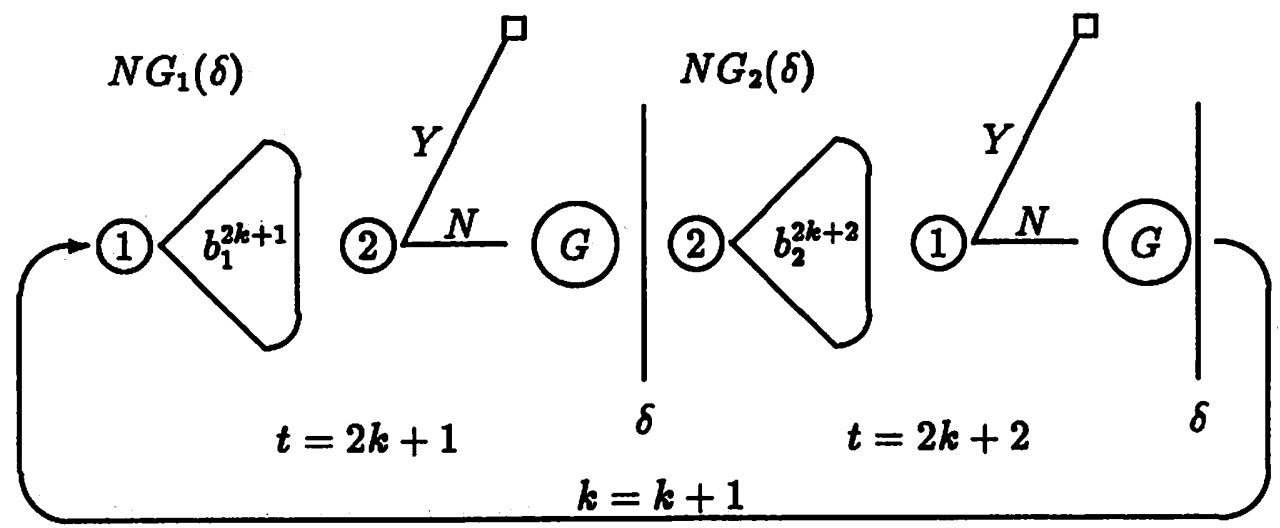

Figure 1: Schematic of a Negotiation Game

surplus. While these negotiations go on the two continue to produce and serve the market, behaving as Cournot firms. The question is what allocations are possible in equilibrium and what strategies are followed during the negotiations.

This situation is modelled as follows: There are two players, indexed by $i=1,2$. Time is discrete and indexed by $t=1,2,3, \ldots$. The time horizon is infinite. Both players discount the future, with their (common) discount factor being denoted by $\delta \in(0,1)$. In every period $t$ in which no agreement has yet been reached, the players play the following constituent game: At the beginning of the period, one player makes a take-it-or-leave-it offer to the other player. The offer is in terms of the players' shares of the surplus resulting from agreement. The other player can then either agree or disagree with this offer. Should he agree, both players receive their share of the surplus from this period onward and their prior strategic relationship, and the game, end. Should he not agree, both players play a simultaneous move game in normal form, called the stage game and denoted $G$, the outcome of which determines their payoffs for this period. Time then advances and the constituent game is repeated. A schematic of the game is given in Figure 1.

First, consider the exit share bargain within each period. The offer and agreement are formulated as in Rubinstein (1982). A proposal by a player is a vector in the unit simplex 
of $\mathbf{R}^{2}$, say $(b, 1-b)$, where $b$ is player 1's share and $(1-b)$ is player 2's share of the surplus. A proposal is denoted just by its first coordinate, $b \in[0,1]$. A player's response to a proposal is either rejection or acceptance, indicated by $N$ and $Y$, respectively. The players are said to reach agreement if one player accepts the other one's proposal. The negotiation game ends when players reach agreement, and the players obtain the same proportion of the surplus, which is given by the proposal which was accepted, in each of the subsequent periods. The paper only deals with the case when the two players make alternating proposals, with player 1 proposing in odd periods and player 2 proposing in even periods.

Next, consider the stage game which is played after the proposal $b$ has been rejected. The stage game is a two-player one-shot game in normal form. It consists of a set of two players, their strategy (action) sets, and their payoff functions, and is given by $G=$ $\left\{A_{1}, A_{2}, u_{1}(\cdot), u_{2}(\cdot)\right\}$. Here, $A_{i}$ is player $i$ 's strategy (action) set, assumed compact, and $u_{i}(\cdot): A \rightarrow \mathbf{R}$ is his payoff function, assumed continuous, where $A=A_{1} \times A_{2}$.

The set $A$ can also be interpreted as the set of outcomes of the stage game $G$. A generic element of the set $A$ is denoted $a=\left(a_{1}, a_{2}\right)$. Let $u(\cdot)=\left(u_{1}(\cdot), u_{2}(\cdot)\right): A \rightarrow \mathbf{R}^{2}$. The set of feasible payoffs of the stage game $G$ is given by the convex hull of $u(A), C o[u(A)]$. Let $m^{i}, i=1,2$, denote the strategy pair leading to player $i$ 's minimax payoff. The set of feasible and individually rational payoffs is then the intersection of $C o[u(A)]$ and $\left\{v \in \mathbf{R}^{2} \mid v_{1} \geq u_{1}\left(m^{1}\right), v_{2} \geq u_{2}\left(m^{2}\right)\right\}$. It is denoted by $F$.

To simplify the analysis, the following assumptions are made:

A1: The players' strategies in $G$ are correlated mixed strategies, and deviations by either player are publicly observable.

A2: The surplus from agreement is normalized to 1 and the stage game $G$ is normalized such that $u_{i}\left(m^{i}\right)=0$ for $i=1,2$. 
A1 implies that the set $A_{i}$ is convex for $i=1,2$; that for any feasible payoff vector $v$, $\exists a \in A$ such that $v=u(a)$; and that the stage game $G$ has at least one Nash equilibrium. A2 is a convenient normalization of the payoff space.

A final assumption on the payoffs is that the surplus from agreement dominates the payoffs from $G$, giving rise to gains from trade. This is given formally by

A3: $\forall a \in A, u_{1}(a)+u_{2}(a) \leq 1$.

Define the negotiation game $N G(\delta)$ to be the game in which 2 players with discount factor $\delta$ play a sequence of constituent games until agreement, where a constituent game is an offer game followed, after rejection, by the stage game $G$, and agreement is the acceptance of a proposal. Let $N G_{i}(\delta)$ be the game in which player $i$ makes the proposal in the first period (note that by convention the first period in $N G_{2}(\delta)$ is an even period). For the sake of brevity, all results will be proven only for $N G_{1}(\delta)$, the proof for $N G_{2}(\delta)$ following in an analogous manner.

Define a type 1 t-period history in the game $N G_{i}(\delta)$ as a finite sequence denoted by $h_{1}(t)=\left(b^{1}, a^{1}, \ldots, b^{t}, a^{t}\right)$, in which $b^{*}$ is the proposal made in period $s$ and $a^{s} \in A$ is the outcome of $G$ in period $s$ after proposal $b^{c}$ had been rejected, for $s=1, \ldots, t$. Let $h_{1}(0)=\emptyset$. A type $1 t$-period history can be decomposed as $h_{1}(t)=b(t) \oplus a(t)$ where

$$
b(t)=\left(b^{1}, \ldots, b^{t}\right) \in[0,1]^{t} ; a(t)=\left(a^{1}, \ldots, a^{t}\right) \in A^{t}
$$

A type $2 t$-period history in the game $N G_{i}(\delta)$ is denoted by $h_{2}(t)=h_{1}(t) \oplus b^{t+1}$, indicating that following the type $1 t$-period history $h_{1}(t), b^{t+1}$ has been proposed in period $(t+1)$.

A type 3 -period history in the game $N G_{i}(\delta)$ is denoted by $h_{3}(t)=h_{2}(t) \oplus\{N\}$, indicating that the proposal $b^{t+1}$ has been rejected in period $(t+1)$. 
The sets of all possible histories of all three types, $H_{1}, H_{2}$ and $H_{3}$, can be written in the usual way by taking the appropriate countably infinite unions over time of the sets of all possible t-period histories. For example for $\left.H_{1}: H_{1}=\cup_{t=0}^{\infty} H_{1}(t)=\cup_{t=0}^{\infty}\left([0,1]^{t} \times A^{t}\right)\right)$.

A strategy combination $f=\left(f_{1}, f_{2}\right)$ for the game $N G_{1}(\delta)$ consists of two functions which map from the sets of all appropriate histories to the sets of all appropriate actions, such that

$$
\begin{array}{ll}
\left(f_{1}, f_{2}\right): & H_{1}(t) \times H_{2}(t) \rightarrow[0,1] \times\{Y, N\} \text { if } t \text { is even } \\
\left(f_{1}, f_{2}\right): & H_{2}(t) \times H_{1}(t) \rightarrow\{Y, N\} \times[0,1] \text { if } t \text { is odd } \\
\left(f_{1}, f_{2}\right): & H_{3} \rightarrow A
\end{array}
$$

The strategy combination $f$ gives the players' instructions on how to play the game in every period, conditional on history. For example, in the odd period $(t+1)$ after the type $1 t$-period history $h_{1}(t), f_{1}\left(h_{1}(t)\right)$ gives player 1's proposal $b^{t+1}, f_{2}\left(h_{2}(t)\right)$ gives player 2's response to player 1's proposal, and $\left(f_{1}\left(h_{3}(t)\right), f_{2}\left(h_{3}(t)\right)\right)$ is the one-shot play of the stage game $G$ in period $(t+1)$ after 1's proposal has been rejected by 2 . The players' actions in an even period are specified analogously.

An outcome path of $N G_{1}(\delta), \pi(T)=\left(b^{1}, a^{1}, b^{2}, a^{2}, \ldots, b^{T},\{Y\}\right)$, can be interpreted to indicate that the proposal $b^{t}$ has been rejected and the stage outcome $a^{t}$ has been played in period $t$ for $1 \leq t<T$, and that the proposal $b^{T}$ has been accepted in period $T$. By convention, $T$ is set to infinity in an outcome path in which the two players never reach agreement. An outcome path of $N G_{1}(\delta)$ can be decomposed as $\pi(T)=b(T) \oplus a(T-1) \oplus\{Y\}$.

The payoff to the players from outcome path $\pi(T)$ is determined by the stage game outcomes in all periods before agreement is reached and by the agreement itself. The average payoffs the players receive from the outcome path $\pi(T)$ are given by

$$
\begin{aligned}
& U_{1}(\pi(T))=(1-\delta) \sum_{t=1}^{T-1} \delta^{t-1} u_{1}\left(a^{t}\right)+\delta^{T-1} b^{T} \\
& U_{2}(\pi(T))=(1-\delta) \sum_{t=1}^{T-1} \delta^{t-1} u_{2}\left(a^{t}\right)+\delta^{T-1}\left(1-b^{T}\right)
\end{aligned}
$$


Since a strategy combination $f$ induces a unique outcome path in the game $N G_{1}(\delta)$, the average payoffs from $f$ can be calculated directly from equations (1) and (2) and the induced outcome path.

\section{Subgame Perfect Equilibria}

In what follows the subgame perfect equilibria (SPE) of the negotiation game $N G_{1}(\delta)$ are characterized. In order to generate some intuition on how the game behaves, two examples are provided.

\subsection{Existence and Two Examples}

Example 1: Consider the negotiation game which consists of a surplus of size 1 and a stage game $G$ with the following payoff matrix:

\begin{tabular}{|c|c|c|}
\hline $1 \backslash 2$ & $C$ & $D$ \\
\hline$C$ & $(.4, .4)$ & $(-.2, .6)$ \\
\hline$D$ & $(.6,-.2)$ & $(0,0)^{*}$ \\
\hline
\end{tabular}

Note that the payoff vector $(0,0)$ is both the minimax and one-shot Nash equilibrium outcome in the stage game $G$. This payoff is also the same as the status quo payoff in the standard Rubinstein game. The following claim should therefore come as no surprise.

Claim 1: The negotiation game of Example 1 has a Subgame Perfect Equilibrium in which player 1's proposal of $1 /(1+\delta)$ is accepted by player 2 in the first period.

The strategies implementing this equilibrium are identical to those implementing the equilibrium in the Rubinstein game, save for the addition of a strategy for $G$. Player 1 proposes $1 /(1+\delta)$ irrespective of the history of the game and rejects any proposal less than $\delta /(1+\delta)$. Player 2 rejects any proposal more than $1 /(1+\delta)$ and proposes $\delta /(1+\delta)$ 
irrespective of the history of the game. Should the stage game $G$ be reached, both players play their Nash equilibrium strategies $D$, irrespective of history. The reader may check that these strategies do indeed form a SPE.

In this equilibrium the Nash equilibrium of the stage game is played in every period in which no agreement has been reached. The SPE of the negotiation game is constructed using the one-shot Nash payoffs in $G$ as the status quo point in every period. Since the strategies in $G$ are Nash and the proposal/reject strategies are history independent, both players have no incentive to deviate in $G$. But then the game reduces (for those strategies) to a bargaining game with a fixed status quo point, and the result obtains. This argument is made formally in the proof to the next theorem, which asserts existence of SPE in negotiation games.

Theorem 1 Suppose that $a^{*} \in A$ is a Nash equilibrium in the stage game $G . \forall \delta \in(0,1)$, $N G_{1}(\delta)$ has a subgame perfect equilibrium in which player $i$ 's proposal $b_{i}^{*}$ is accepted by player $j \neq i$, where

$$
\begin{aligned}
& b_{1}^{*}=\frac{1+\delta u_{1}\left(a^{*}\right)-u_{2}\left(a^{*}\right)}{1+\delta} \\
& b_{2}^{*}=\frac{\delta+u_{1}\left(a^{*}\right)-\delta u_{2}\left(a^{*}\right)}{1+\delta}
\end{aligned}
$$

The equilibrium of Claim 1 is not the only one in the negotiation game of Example 1, however.

Claim 2: In the negotiation game $N G_{1}(\delta)$ of Example 1 the average payoffs $(1-.4) /(1+$ $\delta),(\delta+.4) /(1+\delta))$ can be supported as a subgame perfect equilibrium.

The equilibrium presented in Claim 1 yielded the same average payoffs for the players as a standard Rubinstein bargaining game; namely $1 /(1+\delta), \delta /(1+\delta))$. Player 1 does considerably worse in the equilibrium of Claim 2. In fact, the equilibrium given here yields the worst possible equilibrium payoff for him. Interestingly, the average payoffs in Claim 2 
are the same as those in a Rubinstein bargaining game with a status quo point of $(0, .4)$. As before, the claim will not be proven since it is implied by the theorems to be presented shortly. The reader may, however, check that the strategies which are outlined in the following are subgame perfect.

In general, player 1 proposes $.6 /(1+\delta)$, and player 2 accepts this proposal. Any higher proposal is rejected by 2 and the players play the strategy pair $(C, D)$, yielding a one period payoff of $(-.2, .6)$. In the following even period, if player 1 has not deviated from $C$, player 2 proposes $\left(.2+.4 \delta^{2}\right) / \delta(1+\delta)$ and 1 accepts any proposal at least that big. Player 2 proposes $.6 \delta /(1+\delta)$ instead if 1 deviated from $C$, and 1 accepts any proposal at least that big. Should 1 not accept these offers by player 2 , they play the strategy pair $(D, D)$ in $G$, yielding a one period payoff of $(0,0)$, and it is 1 's turn again to offer $.6 /(1+\delta)$. Finally, should 2 not make the required offers, or should 2 not accept 1's equilibrium offer, the players will follow the equilibrium strategies of Claim 1 from the next subgame on.

These strategies point to the difference in negotiation games from bargaining games: The existence of payoffs during disagreement periods can be exploited to reduce player 1's share of the surplus. Notice that the way they enter the calculations is via player 2's payoff rather than player 1's. In particular, while 1 is required to play the strategy $C$, which is not one shot optimal, his average payoff from doing so is actually the same as if he were just minimaxed, since the following exit offer compensates him. However, player 2 gains from this choice of strategies. Instead of receiving the payoff from minimaxing 1 , zero in this case, he has a positive payoff even after compensating player 1 . Thus, while player 1 is effectively minimaxed, player 2 obtains a higher payoff than he would from minimaxing player 1.

The possibility for these types of strategies does not exist in all negotiation games, however. Consider the following, very similar, negotiation game.

Example 2: The surplus is of size 1, and the stage game $G$ has the following payoff matrix: 


\begin{tabular}{|c|c|c|}
\hline $1 \backslash 2$ & $C$ & $D$ \\
\hline$C$ & $(.4, .4)$ & $(-.8, .8)$ \\
\hline$D$ & $(.8,-.8)$ & $(0,0)^{*}$ \\
\hline
\end{tabular}

Claim 3: The negotiation game of Example 2 has a unique subgame perfect equilibrium. It is given by history independent offers of $1 /(1+\delta)$ by player 1 and $\delta /(1+\delta)$ by player 2 , and the play of $(D, D)$ in $G$ in all periods in which an offer has been rejected.

The stage game in this second example has the same structure as that in the first example, both games being variants of the Prisoners' Dilemma game. In particular, both have a unique Nash equilibrium which is also the mutual minimax, and players have only 2 strategies, of which one is strictly dominated in both games. Nevertheless, the equilibrium sets of the associated negotiation games differ dramatically. Clearly, the usual methods of classifying normal form games are not sufficient to predict the equilibrium set of negotiation games. ${ }^{7}$ The reader may find it instructional to check that strategies analogous to those used in Claim 2 do not allow for a lower payoff for player 1 . Notice in particular that the payoffs do not allow 2 to receive a higher one period disagreement payoff than from minimaxing 1.

\subsection{Optimal Punishments}

The examples above pose the question under what circumstances equilibria other than those based on the play of Nash equilibria in $G$ can be supported. The optimal punishment for player $i$ in $N G_{1}(\delta)$ is defined as that SPE in which player $i$ 's equilibrium payoff is less than or equal to all SPE payoffs of the game. The optimal punishment for player 1 will be derived first. Player 2's optimal punishment can then be derived by analogous arguments.

\footnotetext{
${ }^{7}$ This result may not be that surprising, since all utilities are transferable in negotiation games, whereas the standard theory of normal form games assumes non-transferable utility and only requires a ranking of outcomes by each player.
} 
The derivation of the optimal punishment will proceed in two steps. First, the lower bound of player 1's equilibrium payoffs is computed for the game $N G_{1}(\delta)$. Then, a SPE is constructed such that player 1's average equilibrium payoff achieves this lower bound. It then follows that the equilibrium which has been constructed is in fact the optimal punishment for player 1.

Before the punishments are derived, consider for a moment the type of strategies used as punishments in repeated games. The general flavour of the punishment strategies is that the punishment of player 1 is enforced by restarting the same punishment should 1 deviate from it, and by starting a punishment for player 2 should he fail to punish 1. Here, very similar strategies are employed, only complicated by the fact that the game is not symmetric between even and odd periods and has 3 subgames per period. There is an additional difference, however. This is the fact that player 2 cannot be punished for wrongly accepting a deviating exit offer. Contrary to repeated games, in which a punishment always has a future, ${ }^{8}$ a deviating accept decision in negotiations ends the game, precluding punishment of the deviation. Combined with the fact that exit offers a surplus over continued play, this limits the severity of the punishment which 1 can be made to suffer in $N G_{1}(\delta)$. The reason is that 2 will accept any offer which yields at least as much as punishing 1 , and that 1 will therefore want to make such an offer, since it leaves him better off than delaying or offering 2 any more of this surplus. This points to the necessity of giving player 2 as high a payoff as possible, in order for him to reject the lowest possible offers by 1 .

In order to clarify the role that disagreement period payoffs play in players' offer strategies, the following Lemma, which is also used to prove Theorem 1, is useful. The Lemma concerns Rubinstein type bargaining games with exogenous but time variant status quo points. It upholds Rubinstein's uniqueness result for this class of bargaining games, un-

\footnotetext{
${ }^{8}$ Notice how in finitely repeated games a long enough time span is required, and how the punishments collapse near the time horizon.
} 
der the condition of common discount factors. The interesting point the Lemma makes about equilibrium offers is the fact that only the disagreement payoffs received in periods in which the player does not make an offer enter into the computation of the equilibrium offers. A player's disagreement payoffs in periods in which he himself makes an offer are totally irrelevant to his equilibrium payoffs. Thus, only payer 1's even period payoffs and player 2's odd period payoffs affect the equilibrium offers.

Lemma: In a Rubinstein type bargaining game with alternating offers over the split of a surplus of size 1 in which players have a common discount factor $\delta$ and receive the payoff $\left(u_{1}(t), u_{2}(t)\right)$ in period $t$ if no agreement has yet been reached, and where $u_{1}(t)+u_{2}(t) \leq 1$, the unique subgame perfect equilibrium is that the proposal $b^{t}$ is accepted in period $t$, where $b^{t}$ is given as follows:

If $t$ is odd

$$
b^{t}=\frac{1}{1+\delta}+(1-\delta) \sum_{k=0}^{\infty} \delta^{2 k}\left[\delta u_{1}(t+2 k+1)-u_{2}(t+2 k)\right]
$$

and if $t$ is even

$$
b^{t}=\frac{\delta}{1+\delta}+(1-\delta) \sum_{k=0}^{\infty} \delta^{2 k}\left[u_{1}(t+2 k)-\delta u_{2}(t+2 k+1)\right]
$$

The Lemma is proven in the Appendix, following the method of Shaked and Sutton (1984), whereby the equilibrium proposal for each player and all times is computed under the condition that the players are faced with a known but fixed sequence of disagreement payoffs.

In the light of this, consider again the strategies outlined for implementing the equilibrium of Claim 2. The unusual feature of these strategies is that they call for 1 to play $C$ in $G$ in odd periods, a strategy which is not 1-shot optimal in $G$. In order to make this strategy subgame perfect, player 1 is compensated in the following exit proposal, and his payoff from playing along with the strategy and being compensated is indeed the same as 
his payoff from deviating to the 1-shot optimal strategy $D$ and not being compensated. In even periods player 1 is minimaxed and receives zero. In Example 1, this strategy choice leads to a net gain for player 2 in odd periods, since he obtains 0.6 and compensates 1 by 0.2 . Player 2's 'effective disagreement payoff' in an odd period is thus 0.4 while player 1 has an 'effective disagreement payoff' of 0 in even periods. This explains the fact that the equilibrium shares of the surplus are the same as those of a Rubinstein game with the disagreement payoff $(0,0.4)$.

As the Lemma has shown, a higher disagreement payoff for $\mathbf{2}$ in odd periods will decrease the exit offer made by 1 , while a lower disagreement payoff to 1 in even periods will also decrease the exit offer. Minimaxing 1 in even periods will yield the worst possible payoff to him in even periods. The remaining question is what the highest possible 'effective disagreement payoff' for player 2 is, given a game $G$.

Let $y_{1}^{*}$ denote player 2's highest effective disagreement payoff. Then $y_{1}^{*}$ is given by

$$
y_{1}^{*}=\max _{a \in A}\left\{u_{2}(a)-\left(\max _{a_{1}^{\prime} \in A_{1}} u_{1}\left(a_{1}^{\prime}, a_{2}\right)-u_{1}(a)\right)\right\}
$$

For future reference in strategy profiles, also define the strategy combination in $G$ which achieves $y_{1}^{*}$ as ${ }^{9}$

$$
a^{1}=\operatorname{Arg} \max _{a \in A}\left\{u_{2}(a)-\left(\max _{a_{1}^{\prime} \in A_{1}} u_{1}\left(a_{1}^{\prime}, a_{2}\right)-u_{1}(a)\right)\right\} .
$$

The number $y_{1}^{*}$ gives the maximum difference between player 2's payoff and player 1's best deviation gain over all strategies in $G$, which is, in fact, the maximum payoff 2 can effectively obtain from disagreement in odd periods under the punishment strategies for 1. The value of $y_{1}^{*}$ depends only on the structure of $G$, and A2 and A3 imply $0 \leq y_{1}^{*} \leq 1$. The following theorem gives the lower bounds of player 1's payoffs in negotiation games as a function of player 2's effective disagreement payoff $y_{1}^{*}$.

\footnotetext{
${ }^{9}$ This may, of course, not be unique. While player 1's payoff does not affect the exit offer and exit will occur immediately in equilibrium, assume that the strategy which yields the lowest payof to 1 is chosen.
} 
Theorem 2 Player 1's average equilibrium payoffs in the game $N G_{1}(\delta)\left[N G_{2}(\delta)\right]$ are bounded below by $\frac{1}{1+\delta}\left(1-y_{1}^{*}\right)\left[\frac{\delta}{1+\delta}\left(1-y_{1}^{*}\right)\right]$.

Notice that this lower bound coincides with the Rubinstein solution to a bargaining game with disagreement payoffs of $\left(0, y_{1}^{*}\right)$. The proof of the theorem proceeds by deriving the infimum of player 1's equilibrium payoffs, which is a meaningful concept due to Theorem 1. In doing so, the restrictions imposed by subgame perfection and the fact that $u_{1}(a)+$ $u_{2}(a) \leq 1$ are exploited. Details are in the Appendix.

In the next theorem a subgame perfect equilibrium of $N G_{1}(\delta)\left[N G_{2}(\delta)\right]$ is constructed in which player 1's average equilibrium payoff is $\frac{1}{1+\delta}\left(1-y_{1}^{*}\right)\left[\frac{\delta}{1+\delta}\left(1-y_{1}^{*}\right)\right]$ if $\delta$ is large enough. Theorem 2 then directly implies that this SPE is the optimal punishment equilibrium for player 1 in $N G_{1}(\delta)\left[N G_{2}(\delta)\right]$.

Theorem 3 There exists a $\underline{\delta} \in(0,1)$ such that, $\forall \delta \in(\underline{\delta}, 1)$, the average payoff vector

$$
\left(\frac{1-y_{1}^{*}}{1+\delta}, \frac{\delta+y_{1}^{*}}{1+\delta}\right) \quad\left[\left(\frac{\delta\left(1-y_{1}^{*}\right)}{1+\delta}, \frac{1+\delta y_{1}^{*}}{1+\delta}\right)\right]
$$

can be supported by a subgame perfect equilibrium in the game $N G_{1}(\delta)\left[N G_{2}(\delta)\right]$.

The strategies implementing these payoffs are defined recursively and given below for $N G_{1}(\delta)$. Strategies for $N G_{2}(\delta)$ are analogous. In the strategies, $a^{*}$ refers to a Nash equilibrium strategy in $G$, and $a^{1}$ and $m^{1}$ are as defined previously. ${ }^{10}$

In the first period, players' strategies are

$$
\begin{aligned}
f_{1}\left(h_{1}(0)\right) & =\frac{1-y_{1}^{*}}{1+\delta} \\
f_{2}\left(b^{1}\right) & = \begin{cases}Y & \text { if } b^{1} \leq \frac{1}{1+\delta}\left(1-y_{1}^{*}\right) \\
N & \text { otherwise }\end{cases} \\
\left(f_{1}, f_{2}\right)\left(b^{1} \oplus\{N\}\right) & = \begin{cases}a^{*} & \text { if } b^{1} \leq \frac{1}{1+\delta}\left(1-y_{1}^{*}\right) \\
a^{1} & \text { otherwise }\end{cases}
\end{aligned}
$$

\footnotetext{
${ }^{10}$ Note that the choice of $a^{*}$ affects the value of $\oint$ needed.
} 
Thereafter, $\forall h_{1}(t)=a(t) \oplus b(t) \in H_{1}, h_{2}(t)=a(t) \oplus b(t+1) \in H_{2}$ and $h_{3}(t)=a(t) \oplus b(t+1) \oplus\{N\} \in H_{3}:$

For an odd period $(t+1)$

$$
\begin{aligned}
& f_{1}\left(h_{1}(t)\right)= \begin{cases}\frac{1}{1+\delta}\left(1+\delta u_{1}\left(a^{*}\right)-u_{2}\left(a^{*}\right)\right) & \text { if either }\left(f_{1}, f_{2}\right)\left(h_{3}(t-1)\right)=a^{*} \\
\frac{1}{1+\delta}\left(1-y_{1}^{*}\right) & \text { or } a_{1}^{t}=f_{1}\left(h_{3}(t-1)\right), a_{2}^{t} \neq f_{2}\left(h_{3}(t-1)\right)\end{cases} \\
& f_{2}\left(h_{2}(t)\right)= \begin{cases}Y & \text { if } b^{t+1} \leq f_{11}\left(h_{1}(t)\right) \\
N & \text { otherwise }\end{cases} \\
&\left(f_{1}, f_{2}\right)\left(h_{3}(t)\right)= \begin{cases}a^{*} & \text { if either }\left(f_{1}, f_{2}\right)\left(h_{3}(t-1)\right)=a^{*} \text { or } b^{t+1} \leq f_{1}\left(h_{1}(t)\right) \\
& \text { or } a_{1}^{t}=f_{1}\left(h_{3}(t-1)\right), a_{2}^{t} \neq f_{2}\left(h_{3}(t-1)\right) \\
a^{1} & \text { otherwise }\end{cases}
\end{aligned}
$$

and for an even period $(t+1)$

$$
\begin{aligned}
f_{2}\left(h_{1}(t)\right)= \begin{cases}\frac{1}{1+\delta}\left(\delta+u_{1}\left(a^{*}\right)-\delta u_{2}\left(a^{*}\right)\right) & \text { if either }\left(f_{1}, f_{2}\right)\left(h_{3}(t-1)\right)=a^{*} \\
\frac{\delta}{1+\delta}\left(1-y_{1}^{*}\right) & \text { or } a_{1}^{t}=f_{1}\left(h_{3}(t-1)\right), a_{2}^{t} \neq f_{2}\left(h_{3}(t-1)\right) \\
\frac{1-\delta}{\delta} u_{2}\left(a^{1}\right)+\frac{\delta^{2}-y_{1}^{*}}{\delta(1+\delta)} & \text { if } a_{1}^{t} \neq f_{1}\left(h_{3}(t-1)\right), a_{2}^{t}=f_{2}\left(h_{3}(t-1)\right)\end{cases} \\
f_{1}\left(h_{2}(t)\right)= \begin{cases}Y & \text { if } b^{t+1} \geq f_{2}\left(h_{1}(t)\right) \\
N & \text { otherwise }\end{cases} \\
\left(f_{1}, f_{2}\right)\left(h_{3}(t)\right)= \begin{cases}a^{*} & \text { if either } a_{1}^{t}=f_{1}\left(h_{3}(t-1)\right) ; a_{2}^{t} \neq f_{2}\left(h_{3}(t-1)\right) \\
m^{1} & \text { or } b^{t+1}<f_{2}\left(h_{1}(t)\right) \text { or }\left(f_{1}, f_{2}\right)\left(h_{3}(t-1)\right)=a^{*}\end{cases}
\end{aligned}
$$

The proof of this Theorem first derives the necessary $\underline{\mathcal{E}}$, and then checks the strategy for subgame perfection in each subgame.

Given the result of Theorem 2, Theorem 3 in fact provides the optimal punishments for player 1 in the negotiation games starting with his offer and with 2's offer. By analogous 
arguments, and without proof, the optimal punishment for player 2 can be found. Let

$$
x_{2}^{*}=\max _{a \in A}\left\{u_{1}(a)-\left(\max _{a_{2}^{\prime} \in A_{2}} u_{2}\left(a_{1}, a_{2}^{\prime}\right)-u_{2}(a)\right)\right\}
$$

and

$$
a^{2}=\operatorname{Arg} \max _{a \in A}\left\{u_{1}(a)-\left(\max _{a_{2}^{\prime} \in A_{2}} u_{2}\left(a_{1}, a_{2}^{\prime}\right)-u_{2}(a)\right)\right\}
$$

be player 1's highest effective disagreement payoff in even periods in player 2's punishment, and the strategy combination in $G$ implementing it. As before, $0 \leq x_{2}^{*} \leq 1$. The following theorem gives the optimal punishment payoffs for player 2 as a function of $x_{2}^{*}$.

Theorem 4 There exists a $\delta \in(0,1)$ such that, $\forall \delta \in(\underline{\delta}, 1)$, the average payoff vector

$$
\left(\frac{1+\delta x_{2}^{*}}{1+\delta}, \frac{\delta\left(1-x_{2}^{*}\right)}{1+\delta}\right) \quad\left[\left(\frac{\delta+x_{2}^{*}}{1+\delta}, \frac{1-x_{2}^{*}}{1+\delta}\right)\right]
$$

can be supported by a subgame perfect equilibrium in the game $N G_{1}(\delta)\left[N G_{2}(\delta)\right]$.

In the spirit of the Folk Theorem literature, the characterization of the supportable equilibrium payoffs is for "large enough" discount factors. Therefore the following limiting values are defined as $\delta$ tends to 1 :

$$
\underline{v_{1}}=\frac{1}{2}\left(1-y_{1}^{*}\right) \text { and } \quad \underline{v_{2}}=\frac{1}{2}\left(1-x_{2}^{*}\right) .
$$

The results so far indicate that player $i$ 's equilibrium payoffs in the negotiation game $N G_{i}(\delta)$ are bounded below by $\underline{v_{i}}$. The outstanding question at this point is if indeed all feasible payoffs above the lower bound $\underline{v}_{i}$ can be supported as SPE for "large enough" discount factors. This question is addressed next.

\subsection{Perfect Equilibria in Negotiation Games}

In answer to the question posed above, the following can be shown. 
Theorem 5 For a given feasible payoff vector $\left(v_{1}, v_{2}\right)$ in the negotiation game $N G_{1}(\delta)$ $\left[N G_{2}(\delta)\right]$ such that $\left(v_{1}, v_{2}\right)>\left(\underline{v}_{1}, \underline{v}_{2}\right)$, there exists $\underline{\delta} \in(0,1)$ such that $\forall \delta \in(\underline{\delta}, 1), N G_{1}(\delta)$ $\left[N G_{2}(\delta)\right]$ has a subgame perfect equilibrium with average payoff $\left(v_{1}, v_{2}\right)$.

The equilibrium strategy profiles implementing any such equilibrium are very simple. First, an outcome path which leads to the average payoff $\left(v_{1}, v_{2}\right)$ is found. It consists of the agreement players reach in some period $T$, and the outcomes of the stage game $G$ in every period before agreement is reached. The outcome path is, in general, not unique. In order for it to be applicable, both players must have a future average payoff above their respective minimum payoffs at every point in the path. For any average payoff above the lower bound there exists at least one outcome path with that feature. The following strategies then implement this outcome path.

In every period before the last, the player who makes the proposal demands the whole value of the surplus for himself. Any other offer will be considered a deviation by that player, and he will be punished by implementation of his punishment equilibrium, subject to the fact that the other player accepts a proposal made before the last period if the proposal pays him more than he could obtain if the other player is punished. In the stage game, players play strategies leading to the appropriate outcome for the period as specified in the outcome path. If a player deviates from his strategy in the stage game, he is punished by implementation of his punishment equilibrium. Simultaneous deviations by the players are ignored. This strategy is given formally below.

Let $\pi(T)=\hat{b}(T) \oplus \hat{a}(T-1) \oplus\{Y\}$ be the outcome path of the negotiation game, where $\hat{b}(T)=\left\{\hat{b}^{t}\right\}_{t=1}^{T}$ and $\hat{a}(T-1)=\left\{\hat{a}^{t}\right\}_{t=1}^{T-1}$. Define the indicator function

$$
I D(\cdot): H_{1} \cup H_{2} \cup H_{3} \rightarrow\{0\} \cup\{(i, t) \mid i=1,2 ; 1 \leq t \leq T\}
$$

recursively as follows: at the beginning of period 1 , the history is the empty set and the indicator function takes the value 0, i.e. $I D(\emptyset)=0$. Thereafter, $\forall h_{1}(t)=h_{3}(t-1) \oplus$ 
$\left(a_{1}^{t}, a_{2}^{t}\right) \in H_{1}, h_{2}(t)=h_{1}(t) \oplus b^{t+1} \in H_{2}$, and $h_{3}(t)=h_{2}(t) \oplus\{N\} \in H_{3}$,

$$
\begin{aligned}
& I D\left(h_{1}(t)\right)=\left\{\begin{array}{cl}
(1, t) & \text { if } a_{1}^{t} \neq \hat{a}_{1}^{t} ; a_{2}^{t}=\hat{a}_{2}^{t} \text { and } I D\left(h_{3}(t-1)\right)=0 \\
(2, t) & \text { if } a_{1}^{t}=\hat{a}_{1}^{t} ; a_{2}^{t} \neq \hat{a}_{2}^{t} \text { and } I D\left(h_{3}(t-1)\right)=0 \\
I D\left(h_{3}(t-1)\right) & \text { otherwise }
\end{array}\right. \\
& I D\left(h_{2}(t)\right)= \begin{cases}(1, t+1) & \text { if } b^{t+1} \neq \hat{b}^{t+1} \text { and }(t+1) \text { is odd and } I D\left(h_{1}(t)\right)=0 \\
(2, t+1) & \text { if } b^{t+1} \neq \hat{b}^{t+1} \text { and }(t+1) \text { is even and } I D\left(h_{1}(t)\right)=0 \\
I D\left(h_{1}(t)\right) & \text { otherwise }\end{cases} \\
& I D\left(h_{3}(t)\right)= \begin{cases}(1, t+1) & \text { if } t+1=T \text { and } T \text { is odd and } I D\left(h_{2}(t)\right)=0 \\
(2, t+1) & \text { if } t+1=T \text { and } T \text { is even and } I D\left(h_{2}(t)\right)=0 \\
I D\left(h_{2}(t)\right) & \text { otherwise }\end{cases}
\end{aligned}
$$

The indicator function takes two types of possible values, 0 and $(i, t)$. The value 0 implies that no player has deviated from the proposed path $\pi(T)$. The value $(i, t)$ implies that player $i$ first deviated from the proposed path in period $t$, where $1 \leq t \leq T$.

Let $f^{i j}$ denote the strategy combination in the optimal punishment equilibrium for player $i$ in the game $N G_{j}(\delta)$. The strategies implementing the outcome path $\pi(T)=$ $\hat{b}(T) \oplus \hat{a}(T-1) \oplus\{Y\}$, where

$$
\hat{a}(T-1)=\left\{\hat{a}^{t}\right\}_{t=1}^{T-1} \in A^{T-1} \text { and } \hat{b}(T)=(1,0,1,0, \ldots, \hat{b}),
$$

in $N G_{1}(\delta)$ for large enough $\delta$ then are:

$\forall h_{1}(t) \in H_{1}, h_{2}(t)=h_{1}(t) \oplus b^{t+1} \in H_{2}$, and $h_{3}(t)=h_{2}(t) \oplus\{N\} \in H_{3}$, 
for an odd period $(t+1)$

$$
\begin{aligned}
& f_{1}\left(h_{1}(t)\right)=\left\{\begin{array}{cl}
\hat{b} & \text { if } I D\left(h_{1}(t)\right)=0 \text { and } t+1=T^{*} \\
1 & \text { if } I D\left(h_{1}(t)\right)=0 \text { and } t+1<T^{*} \\
f_{1}^{11}\left(h_{1}(t-s)\right) & \text { if } I D\left(h_{1}(t)\right)=(1, s) \text { for even } s \\
f_{1}^{12}\left(h_{1}(t-s)\right) & \text { if } I D\left(h_{1}(t)\right)=(1, s) \text { for odd } s \\
f_{1}^{21}\left(h_{1}(t-s)\right) & \text { if } I D\left(h_{1}(t)\right)=(2, s) \text { for even } s \\
f_{1}^{22}\left(h_{1}(t-s)\right) & \text { if } I D\left(h_{1}(t)\right)=(2, s) \text { for odd } s
\end{array}\right. \\
& f_{2}\left(h_{2}(t)\right)=\left\{\begin{array}{cl}
Y & \text { if } t+1=T \text { and } I D\left(h_{2}(t)\right)=0 \text { or if } \\
& (1, t+1) \text { and } 1-b^{t+1} \geq(1-\delta) u_{2}\left(a^{t}\right) \\
N & \text { otherwise } \\
f_{2}^{11}\left(h_{2}(t-s)\right) & \text { if } I D\left(h_{2}(t)\right)=(1, s) \text { for even } s \leq t \\
f_{2}^{12}\left(h_{2}(t-s)\right) & \text { if } I D\left(h_{2}(t)\right)=(1, s) \text { for odd } s \leq t \\
f_{2}^{21}\left(h_{2}(t-s)\right) & \text { if } I D\left(h_{2}(t)\right)=(2, s) \text { for even } s \leq t \\
f_{2}^{22}\left(h_{2}(t-s)\right) & \text { if } I D\left(h_{2}(t)\right)=(2, s) \text { for odd } s \leq t
\end{array}\right.
\end{aligned}
$$

for an even period $(t+1)$,

$$
f_{1}\left(h_{2}(t)\right)=\left\{\begin{array}{cl}
Y & \text { if } t+1=T \text { and } I D\left(h_{2}(t)\right)=0 \text { or if } I D\left(h_{2}(t)\right)= \\
& (2, t+1) \text { and } b^{t+1} \geq(1-\delta) u_{1}\left(a^{*}\right)+\frac{\delta}{1+\delta}\left(\delta+x_{2}^{*}\right) \\
N & \text { otherwise } \\
f_{1}^{11}\left(h_{2}(t-s)\right) & \text { if } I D\left(h_{2}(t)\right)=(1, s) \text { for even } s \leq t \\
f_{1}^{12}\left(h_{2}(t-s)\right) & \text { if } I D\left(h_{2}(t)\right)=(1, s) \text { for odd } s \leq t \\
f_{1}^{21}\left(h_{2}(t-s)\right) & \text { if } I D\left(h_{2}(t)\right)=(2, s) \text { for even } s \leq t \\
f_{1}^{22}\left(h_{2}(t-s)\right) & \text { if } I D\left(h_{2}(t)\right)=(2, s) \text { for odd } s \leq t
\end{array}\right.
$$




$$
f_{2}\left(h_{1}(t)\right)=\left\{\begin{array}{cl}
\hat{b} & \text { if } I D\left(h_{1}(t)\right)=0 \text { and } t+1=T^{*} \\
0 & \text { if } I D\left(h_{1}(t)\right)=0 \text { and } t+1<T^{*} \\
f_{2}^{11}\left(h_{1}(t-s)\right) & \text { if } I D\left(h_{1}(t)\right)=(1, s) \text { for even } s \\
f_{2}^{12}\left(h_{1}(t-s)\right) & \text { if } I D\left(h_{1}(t)\right)=(1, s) \text { for odd } s \\
f_{2}^{21}\left(h_{1}(t-s)\right) & \text { if } I D\left(h_{1}(t)\right)=(2, s) \text { for even } s \\
f_{2}^{22}\left(h_{1}(t-s)\right) & \text { if } I D\left(h_{1}(t)\right)=(2, s) \text { for odd } s
\end{array}\right.
$$

for both odd and even periods $(t+1)$,

$$
f\left(h_{3}(t)\right)=\left\{\begin{array}{cl}
\hat{a} & \text { if } I D\left(h_{3}(t)\right)=0 \\
a^{*} & \text { if } I D\left(h_{3}(t)\right)=(*, t+1) \\
f^{11}\left(h_{3}(t-s)\right) & \text { if } I D\left(h_{3}(t)\right)=(1, s) \text { for even } s \leq t \\
f^{12}\left(h_{3}(t-s)\right) & \text { if } I D\left(h_{3}(t)\right)=(1, s) \text { for odd } s \leq t \\
f^{21}\left(h_{3}(t-s)\right) & \text { if } I D\left(h_{3}(t)\right)=(2, s) \text { for even } s \leq t \\
f^{22}\left(h_{3}(t-s)\right) & \text { if } I D\left(h_{3}(t)\right)=(2, s) \text { for odd } s \leq t
\end{array}\right.
$$

Theorem 5 characterizes all subgame perfect equilibria of negotiation games. It shows that all payoffs above the optimal punishment payoffs can be supported. This fact has various implications. For one, there is quite generally a multiplicity of equilibria, and many feasible outcomes can be supported in equilibrium. While there will be a range of efficient equilibria along the bargaining frontier, this multiplicity implies that Pareto inefficient outcomes can also be an equilibrium. In the context of this model this implies delay, the fact that parties may not agree to a split of the surplus right away. This delay does not depend on the discount factor, unlike in some other models of delay in bargaining. Indeed, as the discount factor approaches unity delay does not get shorter. In Example 1, for instance, infinite delay can be supported for any discount factor larger than one half.

Delay is governed instead by the structure of the stage game and the size of the surplus which agreement yields over continued play of the stage game, the size of the gains 
from trade. Delay is not related to informational asymmetries. The model has a perfect information environment, and thus delay is not due to signaling or uncertainty, as in some other models.

Finally, Theorem 5 shows that the pure existence of strategic payoffs in disagreement periods is not sufficient to invalidate Rubinstein's result of immediate settlement. While one can generally expect them to lead to a multiplicity of equilibria, Example 2 shows that that is not a foregone conclusion. It is sufficient to compute $x_{2}^{*}$ and $y_{1}^{*}$ to determine if multiplicity - and delay - can occur. Only if both are equal to zero will there be a unique equilibrium and no delay.

\section{Discussion}

The previous sections have presented a model of negotiations and characterized its equilibria. The model built upon two extant models of dynamic allocation, the bargaining model of Rubinstein, and the repeated game model. This made it possible to account more realistically for a characteristic of negotiations, namely the fact that parties have strategic payoffs during the negotiations if time is not trivial. Most extant bargaining models do not consider this circumstance. The set of subgame perfect equilibrium payoffs of the negotiation model was characterized as any payoffs above the optimal punishment equilibrium payoffs for the players, which in turn were shown to depend in a simple way on the payoff structure of the stage game played in disagreement periods. The relevant magnitude is the highest effective disagreement payoff the punisher can obtain in periods in which it is his turn to accept or reject offers. This was shown to be easily computed as the maximal difference between the punisher's payoff and the punishee's best deviation gain in the stage game.

The negotiation model was introduced as an alternative to the bargaining and repeated game models. The fact that parties have strategic payoffs during their attempts to agree 
on an allocation - a characteristic not accounted for by the bargaining model - and that any extant relationship which generates these payoffs is of endogenous length - a fact not accounted for by repeated game models - made this new model necessary. The results which have been presented confirm this analysis.

The Lemma presented in Section 3.2 shows that Rubinstein's bargaining model can easily be adapted to deal with exogenous non-stationary status quo points, but Claim 2 and Theorems 3 to 5 show that endogeneity of the status quo point can indeed affect the equilibrium outcome significantly. Theorems 3 and 4 imply a simple test if it does: If $y_{1}^{*}$ and $x_{2}^{*}$ as given by equations (3) and (5) are both equal to zero, the Rubinstein bargaining game is sufficient to analyse the situation.

It was shown that the model extends the analysis of delay in bargaining. It is well known that the original bargaining model can not generate delay. However, delay is commonly observed in situations which are taken to involve bargaining. Therefore, several extensions have been proposed in the past to deal with this aspect. One approach has been to relax the assumption of complete information. Models with both one- and two-sided incomplete information have been brought forward and have been shown to be able to generate delay. ${ }^{11}$ Delay in these types of model generally has a signalling function, since valuation is private information and the cost of delay depends on it.

A more recent approach, which is closely related to the one taken here, is that of Haller and Holden (1990) and Fernandez and Glazer (1991). The model in their papers derives from the realization that delay and strike are not the same. Instead, the decision to strike is modeled explicitly. Both sets of authors show that multiple equilibria exist in such a framework, and that delay can be supported in equilibrium without requiring incomplete information.

\footnotetext{
${ }^{11}$ A very partial list of such papers includes Admati and Perry (1987), Gul and Sonnenschein (1988), Chaterjee and Samuelson (1987), Ausubel and Deneckere (1989). A survey of related literature can be found in Wilson (1987).
} 
The negotiation model represents a considerable strengthening of this latter result. In both Haller and Holden, and Fernandez and Glazer, there is no surplus to be gained from agreement, since new wage offers and the old wage bargain lie on the same frontier. In the negotiation model, in contrast, there can exist a substantial surplus while delay is still an equilibrium. The negotiation model thus addresses cases where there are gains from trade, while upholding the result that delay can occur under perfect information. The model also allows for much richer strategies during disagreement. In the context of wage negotiations, for example, it is easy to incorporate such labour action as work to rule or the employment of strike breakers into the analysis.

The current investigation largely derived from an attempt to endogenize the time horizon in repeated games by allowing parties to exit. ${ }^{12}$ One implication of the Folk Theorem literature in repeated games is that any feasible and individually rational payoff can be supported as equilibrium in infinitely repeated games, and in finite games of sufficient length under a dimensionality condition. ${ }^{13}$ An important implication of these results is that inefficient outcomes can be equilibria. While the current model generally restricts the equilibrium set as compared to the Folk Theorems, it strengthens this latter implication. Even if it is possible to end the game with an efficient payoff, as it is here, inefficient outcomes still can be an equilibrium. The model also implies that some care must be taken in choosing models, since a negotiation model may be observationally similar to a finitely repeated game if the exit agreement, for example, is hard to observe. Note here, that the stage game in Example 1 would have a unique equilibrium in a finitely repeated game of any length, but that any length of apparently repeated play can be supported as outcome

\footnotetext{
${ }^{12}$ As a matter of fact, all Theorems hold in a corresponding fashion if the order of subgames in a period is reversed, such that the stage game is played first and then an exit offer is made which, if accepted, will determine payoffs from the next period on.

${ }^{13}$ See, for example, Abreu (1988), Abreu, Pearce, Stacchetti (1990), Benoit and Krishna (1985), Fudenberg (1990) and Fudenberg and Maskin (1985).
} 
of a negotiation model - with payoffs which are consistent only with infinitely repeated play in a repeated game model.

In the presentation of the model certain assumptions were made for analytical convenience. While some are minor, the relaxation of others could be the subject of future work in this area. The assumption of a common discount factor is clearly minor, since all results require a sufficiently high discount factor beforehand. ${ }^{14}$ Most of the cause of bargaining power in this model is furthermore to be suspected in the stage game, not different time preferences, thus diminishing the case for separate discount factors.

There were two assumptions made on the payoff spaces. One is the restriction that every payoff in $G$ is dominated by some exit payoff. This assumption is economically motivated - there are gains from trade in negotiations, not just a redistribution. The result of delay in equilibrium is also stronger under this assumption, due to the implied inefficiency. An obvious avenue for future work, however, is an extension to the case where the bargaining frontier intersects the payoff space of $G .^{15}$

This raises the second assumption, the shape of the bargaining frontier, which is here assumed to be a straight line. This assumption could be relaxed to allow for an arbitrary bargaining frontier - and in particular for a frontier that coincides with that of the stage game. This latter possibility is reminiscent of the work by Okada (1986), although he uses a very different focus and completely different framework of analysis. It may, however, provide an alternative approach to the question of long-term contracting which he addresses.

In closing, let it be said that the negotiation model presented here provides an alternative approach to modelling dynamic allocation. The model may provide a framework to

\footnotetext{
${ }^{14}$ It should be noted, however, that the Lemma will not hold for sufficiently disparate discount factors. This is due to the fact that agents may evaluate future payoff paths too differently, and thus an acceptable offer may not be made.

${ }^{15}$ The case where the bargaining frontier is entirely inside the payoff space of $G$ is uninteresting: the usual Folk Theorem for infinitely repeated games will continue to hold.
} 
introduce non-static payoffs. In the context of dynamic allocation, it is conceivable that players' actions during negotiations not only affect their current payoffs but also the structure and size of future payoffs, for example the size of the surplus. A protracted strike, for example, may cost market share. A model incorporating such dynamic payoffs will be another step closer to being a complete model of dynamic allocation. 


\section{Appendix}

\section{Proof to Lemma, Section 3.2}

Following Shaked and Sutton (1984), the equilibrium proposals in every period are derived for the bargaining game with a fixed sequence of disagreement payoffs $\{u(t)\}_{t=1}^{\infty}$.

Assume that the set of equilibrium payoffs in such a game is not empty. Let $M_{i}^{t}$ and $m_{i}^{t}$ be the supremum and infimum of player $i$ 's average equilibrium payoffs in the subgame that starts in period $t$, for $i=1,2$ and $t \geq 1$.

First, consider players' strategies in an odd period $t$ in which player 1 makes the proposal and player 2 makes the response. Player 2's payoff from rejecting is $u_{2}(t)$ in period $t$ and a SPE payoff from period $(t+1)$ on which is bounded between $m_{2}^{t+1}$ and $M_{2}^{t+1}$. Therefore, player 2 will always reject if his payoff in the proposal is less than $(1-\delta) u_{2}(t)+\delta m_{2}^{t+1}$, and always accept if his payoff in the proposal is more than $(1-\delta) u_{2}(t)+\delta M_{2}^{t+1}$. Subgame perfection requires that player 1 's proposal, $b^{t}$, should satisfy

$$
(1-\delta) u_{2}(t)+\delta m_{2}^{t+1} \leq 1-b^{t} \leq(1-\delta) u_{2}(t)+\delta M_{2}^{t+1}
$$

which implies that $m_{1}^{t}$ and $M_{1}^{t}$ satisfy the following inequalities

$$
\begin{aligned}
& m_{1}^{t} \geq 1-(1-\delta) u_{2}(t)-\delta M_{2}^{t+1} \\
& M_{1}^{t} \leq 1-(1-\delta) u_{2}(t)-\delta m_{2}^{t+1}
\end{aligned}
$$

Considering players' strategies in the following even period $(t+1)$, we have

$$
\begin{aligned}
& m_{2}^{t+1} \geq 1-(1-\delta) u_{1}(t+1)-\delta M_{1}^{t+2} \\
& M_{2}^{t+1} \leq 1-(1-\delta) u_{1}(t+1)-\delta m_{1}^{t+2}
\end{aligned}
$$

Substituting (4) into (1), (3) into (2), (2) into (3), and (1) into (4), with appropriate updating, yields

$$
m_{1}^{t} \geq 1-(1-\delta) u_{2}(t)-\delta\left[1-(1-\delta) u_{1}(t+1)-\delta m_{1}^{t+2}\right]
$$




$$
\begin{aligned}
M_{1}^{t} & \leq 1-(1-\delta) u_{2}(t)-\delta\left[1-(1-\delta) u_{1}(t+1)-\delta M_{1}^{t+2}\right] \\
m_{2}^{t+1} & \geq 1-(1-\delta) u_{1}(t+1)-\delta\left[1-(1-\delta) u_{2}(t+2)-\delta m_{2}^{t+3}\right] \\
M_{2}^{t+1} & \leq 1-(1-\delta) u_{1}(t+1)-\delta\left[1-(1-\delta) u_{2}(t+2)-\delta M_{2}^{t+3}\right]
\end{aligned}
$$

Recursive substitution on equations (5), (6), (7) and (8) yields, for odd $t$,

$$
\begin{aligned}
m_{1}^{t} & \geq \sum_{k=0}^{\infty}\left[1-(1-\delta) u_{2}(t+2 k)-\delta\left[1-(1-\delta) u_{1}(t+2 k+1)\right]\right] \\
M_{1}^{t} & \leq \sum_{k=0}^{\infty}\left[1-(1-\delta) u_{2}(t+2 k)-\delta\left[1-(1-\delta) u_{1}(t+2 k+1)\right]\right] \\
m_{2}^{t+1} & \geq \sum_{k=0}^{\infty}\left[1-(1-\delta) u_{1}(t+2 k+1)-\delta\left[1-(1-\delta) u_{2}(t+2 k+2)\right]\right] \\
M_{2}^{t+1} & \leq \sum_{k=0}^{\infty}\left[1-(1-\delta) u_{1}(t+2 k+1)-\delta\left[1-(1-\delta) u_{2}(t+2 k+2)\right]\right]
\end{aligned}
$$

Further simplification then yields that

$$
\begin{aligned}
b^{t} & \leq m_{1}^{t} \leq M_{1}^{t} \leq b^{t} \quad \text { if } t \text { is odd } \\
1-b^{t} & \leq m_{2}^{t} \leq M_{2}^{t} \leq 1-b^{t} \text { if } t \text { is even }
\end{aligned}
$$

where $b^{t}$ is as given in the Lemma. (13) and (14) imply that the infima and suprema coincide, and thus if an equilibrium exists in the game, it must be unique in terms of payoffs.

It remains to be shown that an equilibrium exists for the game. Consider the following strategies: in period $t$, the player who makes the proposal will propose $b^{t}$, and the player who makes the response will accept all proposals that he weakly prefers to $b^{t}$ and reject all others.

By construction of $b^{t}$, the player $i$ who makes the response in period $t$ is just indifferent between accepting $b^{t}$ and waiting to propose $b^{t+1}$ in the next period, collecting $u_{i}(t)$ in the meantime. Therefore, rejecting proposals which are not preferred to $b^{t}$ and accepting those which are is player $i$ 's best strategy. This implies that any proposal which is preferred to $b^{t}$ 
by the proposing player will be rejected. It then is easy to show that the assumption that $u_{1}(t)+u_{2}(t) \leq 1$ implies that

$$
\begin{aligned}
b^{t} & \geq(1-\delta) u_{1}(t)+\delta b^{t+1} & & \text { if } t \text { is odd } \\
\left(1-b^{t}\right) & \geq(1-\delta) u_{2}(t)+\delta\left(1-b^{t+1}\right) & & \text { if } t \text { is even }
\end{aligned}
$$

and thus the proposing player prefers the proposal he is to make according to his equilibrium strategy over deviating and waiting for one period. The strategy profile is, therefore, a subgame perfect equilibrium of the bargaining game for the given sequence of disagreement payoffs.

Q.E.D.

\section{Proof to Theorem 1, Section 3.1}

The proof will show that the equilibrium claimed in the Theorem is a special case of the Lemma of Section 3.2. First, note that the disagreement outcome in every period is a Nash equilibrium of the stage game and that all proposals are history independent. Therefore, neither player will deviate in the stage game from $a^{*}$ individually, since he cannot increase his payoff in the current period or thereafter by doing so. Thus, a fixed disagreement payoff is given by $u\left(a^{*}\right)$ for every period without agreement. The Lemma gives the equilibrium proposals in the unique SPE of a bargaining game with a fixed sequence of disagreement payoffs. These proposals are uniquely determined by the disagreement payoffs. Here, $u_{i}(t)=u_{i}\left(a^{*}\right) \forall t \geq 1$. The equilibrium outcome is that player 1's [2's] proposal

$$
b_{1}^{*}=\frac{1+\delta u_{1}\left(a^{*}\right)-u_{2}\left(a^{*}\right)}{1+\delta} \quad\left[b_{2}^{*}=\frac{\delta+u_{1}\left(a^{*}\right)-\delta u_{2}\left(a^{*}\right)}{1+\delta}\right]
$$

is accepted in the first period of the game $N G_{1}(\delta)\left[N G_{2}(\delta)\right]$.

In equilibrium, player $i$ will always propose $b_{i}^{*}$ and only reject proposals which are not preferred to $b_{j}^{*}$ for $j \neq i$. After any rejection, players will play the Nash equilibrium $a^{*}$ in the stage game. The equilibrium strategies for $N G_{1}(\delta)$ are given as follows. $\forall h_{1}(t) \in H_{1}$, 
$h_{2}(t)=h_{1}(t) \oplus b^{t+1} \in H_{2}$ and $h_{3}(t) \in H_{3}:$

for an odd period $(t+1)$,

$$
\begin{aligned}
f_{1}\left(h_{1}(t)\right) & =\frac{1}{1+\delta}\left(1+\delta u_{1}\left(a^{*}\right)-u_{2}\left(a^{*}\right)\right) \\
f_{2}\left(h_{2}(t)\right) & = \begin{cases}Y & \text { if } b^{t+1} \leq f_{1}\left(h_{1}(t)\right) \\
N & \text { otherwise }\end{cases} \\
f\left(h_{3}(t)\right) & =a^{*} \in A
\end{aligned}
$$

for an even period $(t+1)$,

$$
\begin{aligned}
f_{2}\left(h_{1}(t)\right) & =\frac{1}{1+\delta}\left(\delta+u_{1}\left(a^{*}\right)-\delta u_{2}\left(a^{*}\right)\right) \\
f_{1}\left(h_{2}(t)\right) & = \begin{cases}Y & \text { if } b^{t+1} \geq f_{2}\left(h_{1}(t)\right) \\
N & \text { otherwise }\end{cases} \\
f\left(h_{3}(t)\right) & =a^{*} \in A
\end{aligned}
$$

Q.E.D.

\section{Proof to Theorem 2, Section 3.2}

The proof proceeds by deriving the infima of the set of average subgame perfect equilibrium payoffs, taking assumption A2 and subgame perfection into account. Theorem 1 states that $N G_{i}(\delta)$ has, at least, one subgame perfect equilibrium $\forall \delta \in(0,1)$. Therefore, the set of average payoffs of the SPEs in the negotiation game $N G_{i}(\delta)$ is not empty, $\forall \delta \in(0,1)$ and $i=1,2$. Given $\delta \in(0,1)$, let $m_{1}(\delta)$ be the infimum of player 1 's average equilibrium payoffs in $N G_{1}(\delta)$. In the game $N G_{2}(\delta)$, since player 1 can guarantee himself a payoff of 0 in the current period, and his average payoff from the next period on cannot be less than $m_{1}(\delta)$, player 1's average equilibrium payoffs are bounded below by $\delta m_{1}(\delta)$.

By the definition of the infimum, $\forall \epsilon>0, N G_{1}(\delta)$ has a SPE with average payoff $\left(x_{1}, y_{1}\right)$ such that

$$
m_{1}(\delta) \leq x_{1} \leq m_{1}(\delta)+\epsilon
$$


If $x_{1}+y_{1}<1$, it must be the case that player 1's proposal is rejected in the first period of $N G_{1}(\delta)$. Construct a new SPE whose strategies are the same as those in the equilibrium with the payoff $\left(x_{1}, y_{1}\right)$, but in which player 2 only accepts the proposal $x_{1}$ in the first period. If player 2 rejects $x_{1}$, the strategy is the same as when player 2 rejects player 1's equilibrium proposal in the equilibrium with payoff $\left(x_{1}, y_{1}\right)$. This new SPE is efficient and the average payoff vector is $\left(x_{1}, 1-x_{1}\right)$. Therefore assume without loss of generality that

$$
x_{1}+y_{1}=1
$$

In a SPE of $N G_{1}(\delta)$, if player 2 rejects player 1 's proposal in the first period, players must play one stage game outcome, say $a \in A$, and one of the SPEs in $N G_{2}(\delta)$, the payoff of which is, say, $\left(x_{2}(a), y_{2}(a)\right)$, where $x_{2}(a)+y_{2}(a) \leq 1$. Therefore, if player 2 rejects player 1 's proposal in the first period of $N G_{1}(\delta)$, player 2's average payoff is bounded above by the maximum of all possible continuation payoffs. Subgame perfection implies that 2 will certainly accept a proposal if his payoff is more than the maximum of his continuation payoffs, and that player 1 will propose $x_{1}$ in the first period of $N G_{1}(\delta)$ only if

$$
y_{1} \leq \max _{a \in A}\left\{(1-\delta) u_{2}(a)+\delta y_{2}(a)\right\}
$$

However, if player 2 does reject player 1's proposal, player 1 should not deviate from $a \in A$ in the stage game. Subgame perfection, then, requires that

$$
\begin{aligned}
(1-\delta) \max _{a_{1}^{\prime} \in A_{1}} u_{1}\left(a_{1}^{\prime}, a_{2}\right)+\delta^{2} m_{1}(\delta) & \leq(1-\delta) u_{1}(a)+\delta x_{2}(a) \\
& \leq(1-\delta) u_{1}(a)+\delta\left(1-y_{2}(a)\right)
\end{aligned}
$$

which implies that

$$
\delta y_{2}(a) \leq \delta\left(1-\delta m_{1}(\delta)\right)-(1-\delta)\left(\max _{a_{1}^{\prime} \in A_{1}} u_{1}\left(a_{1}^{\prime}, a_{2}\right)-u_{1}(a)\right)
$$

Substituting (18) into (17), and using the definition of $y_{1}^{*}$ from the text, one obtains

$$
\begin{aligned}
y_{1} & \leq(1-\delta) \max _{a \in A}\left\{u_{1}(a)+u_{2}(a)-\max _{a_{1}^{\prime} \in A_{1}} u_{1}\left(a_{1}^{\prime}, a_{2}\right)\right\}+\delta\left(1-\delta m_{1}(\delta)\right) \\
& =(1-\delta) y_{1}^{*}+\delta\left(1-\delta m_{1}(\delta)\right)
\end{aligned}
$$


Together with (15) and (16), this implies

$$
\begin{aligned}
1-m_{1}(\delta)-\epsilon & \leq 1-x_{1}=y_{1} \leq(1-\delta) y_{1}^{*}+\delta\left(1-\delta m_{1}(\delta)\right) \\
\Rightarrow m_{1}(\delta) & \geq \frac{1-y_{1}^{*}}{1+\delta}-\frac{\epsilon}{1-\delta^{2}}
\end{aligned}
$$

Since $\epsilon$ can be chosen arbitrarily small, the last inequality implies that $m_{1}(\delta)$ is greater than or equal to $\frac{1}{1+\delta}\left(1-y_{1}^{*}\right)$. Moreover, player 1's average equilibrium payoffs in $N G_{2}(\delta)$ are bounded below by $\delta m_{1}(\delta)$, which is greater than or equal to $\frac{\delta}{1+\delta}\left(1-y_{1}^{*}\right)$.

Q.E.D.

\section{Proof to Theorem 3, Section 3.2}

Note that the payoffs correspond to the perfect equilibrium for a bargaining game with the disagreement payoff $\left(0, y_{1}^{*}\right)$ in every period. If $\left(0, y_{1}^{*}\right)$ is a Nash equilibrium outcome of the stage game $G$, then the result follows from Theorem 1 . If $\left(0, y_{1}^{*}\right)$ is not a Nash equilibrium of $G$, the proof is lengthy. The necessary $\delta$ will be derived first. Then subgame perfection of the given strategy for $\delta \geq \underline{\delta}$ will be verified.

Suppose $a^{*}$ is a Nash equilibrium in the stage game $G$. The definition of $y_{1}^{*}$ implies that $y_{1}^{*} \geq u_{2}\left(a^{*}\right)$. Since $u_{1}\left(a^{*}\right) \geq 0$ and $\left(0, y_{1}^{*}\right) \neq u\left(a^{*}\right)$, it must be that $y_{1}^{*}+u_{1}\left(a^{*}\right)-u_{2}\left(a^{*}\right)>0$. Let $a^{1} \in A$ such that

$$
x_{1}^{*}+y_{1}^{*}=u_{1}\left(a^{1}\right)+u_{2}\left(a^{1}\right) \text { and } x_{1}^{*}=\max _{a_{1}^{\prime} \in A_{1}} u_{1}\left(a_{1}^{\prime}, a_{2}^{1}\right)
$$

Let $d=\max \left[u_{i}\left(a^{\prime}\right)-u_{i}\left(a^{\prime \prime}\right)\right], \forall a^{\prime}, a^{\prime \prime} \in A$ and $i=1,2$. Since the set $u(A)$ is compact, $d$ must be finite. Consider the following three functions of $\delta \in(0,1]$,

$$
\begin{aligned}
& c_{1}(\delta)=\frac{\delta}{1+\delta}\left[y_{1}^{*}+\delta u_{1}\left(a^{*}\right)-\delta^{2} u_{2}\left(a^{*}\right)\right]-(1-\delta)\left[d+u_{2}\left(a^{1}\right)\right] \\
& c_{2}(\delta)=\frac{\delta}{1+\delta}\left[y_{1}^{*}+\delta u_{1}\left(a^{*}\right)-u_{2}\left(a^{*}\right)\right]-(1-\delta) d \\
& c_{3}(\delta)=y_{1}^{*}-\left(1-\delta^{2}\right) u_{2}\left(a^{1}\right)-\delta^{2} u_{2}\left(a^{*}\right)+\delta u_{1}\left(a^{*}\right)
\end{aligned}
$$

Since these three functions are positive and continuous at $\delta=1$, there must exist $\delta \in(0,1)$ such that, $\forall \delta \in(\underline{\delta}, 1)$, the functions $c_{1}(\delta), c_{2}(\delta)$ and $c_{3}(\delta)$ are positive. Equivalently, 
$\forall \delta \in(\underline{\delta}, 1)$, the following three inequalities hold

$$
\begin{aligned}
(1-\delta) d & \leq \frac{\delta+y_{1}^{*}}{1+\delta}-(1-\delta) u_{2}\left(a^{1}\right)-\frac{\delta}{1+\delta}\left[1-u_{1}\left(a^{*}\right)+\delta u_{2}\left(a^{*}\right)\right] \\
(1-\delta) d & \leq \frac{\delta}{1+\delta}\left[\delta+y_{1}^{*}\right]-\frac{\delta}{1+\delta}\left[\delta-\delta u_{1}\left(a^{*}\right)+u_{2}\left(a^{*}\right)\right] \\
\frac{1-\delta}{\delta} u_{2}\left(a^{1}\right) & +\frac{\delta^{2}-y_{1}^{*}}{\delta(1+\delta)} \leq \frac{1}{1+\delta}\left(\delta+u_{1}\left(a^{*}\right)-\delta u_{2}\left(a^{*}\right)\right)
\end{aligned}
$$

This concludes the derivation of $\underline{\delta}$.

Consider the strategy for $N G_{1}(\delta)$ which was given in the text. The subgame perfection of the strategy will be proven by exhaustive consideration of all subgames.

In an odd period $(t+1)$, there are two cases to be considered.

Case 1: either $f\left(h_{3}(t-1)\right)=a^{*}$; or $a_{1}^{t}=f_{1}\left(h_{3}(t-1)\right), a_{2}^{t} \neq f_{2}\left(h_{3}(t-1)\right)$; or $b^{t+1} \leq f_{1}\left(h_{1}(t)\right)$. Player 2 is the last deviator, i.e. he either deviated in the negotiation game before period $(t-1)$, or in the stage game in period $t$, or rejected a proposal which should have been accepted in period $(t+1)$. The disagreement payoff will be $u\left(a^{*}\right)$ for every period thereafter. Since $a^{*}$ is a Nash equilibrium in the stage game, Theorem 1 implies that the strategy $f$ induces a perfect equilibrium in such a subgame.

\section{Case 2: otherwise}

$f\left(h_{3}(t)\right)=a^{1}$. If player 1 were to deviate from $a^{1}$, according to the strategy, player 2 will propose $\frac{\delta}{1+\delta}\left(1-y_{1}^{*}\right)$ instead of $\frac{1-\delta}{\delta} u_{2}\left(a^{1}\right)+\frac{1}{\delta(1+\delta)}\left(\delta^{2}-y_{1}^{*}\right)$ in period $(t+2)$. Comparing player 1's payoffs, one obtains

$$
\begin{aligned}
(1-\delta) u_{1}\left(a^{1}\right)+(1-\delta) u_{2}\left(a^{1}\right)+\frac{\delta^{2}-y_{1}^{*}}{1+\delta} & =(1-\delta)\left[u_{1}\left(a^{1}\right)+u_{2}\left(a^{1}\right)\right]+\frac{\delta^{2}-y_{1}^{*}}{1+\delta} \\
=(1-\delta)\left(x_{1}^{*}+y_{1}^{*}\right)+\frac{\delta^{2}-y_{1}^{*}}{1+\delta} & =(1-\delta) x_{1}^{*}+\frac{\delta^{2}}{1+\delta}\left(1-y_{1}^{*}\right) \\
& =(1-\delta) \max _{a_{1}^{\prime} \in A_{1}} u_{1}\left(a_{1}^{\prime}, a_{2}^{1}\right)+\delta \frac{\delta}{1+\delta}\left(1-y_{1}^{*}\right)
\end{aligned}
$$

Therefore, player 1 will not deviate from $a^{1}$. 
If player 2 were to deviate from $a^{1}$, player 2 will demänd $\frac{1}{1+\delta}\left(1-u_{1}\left(a^{*}\right)+\delta u_{2}\left(a^{*}\right)\right)$ instead of $\frac{\delta+y_{i}^{*}}{\delta(1+\delta)}-\frac{1-\delta}{\delta} u_{2}\left(a^{1}\right)$ in period $(t+2)$. Inequality (20) implies that

$$
\begin{aligned}
(1-\delta)\left[\max _{a_{2}^{\prime} \in A_{2}} u_{2}\left(a_{1}^{1}, a_{2}^{\prime}\right)\right. & \left.-u_{2}\left(a^{1}\right)\right] \leq(1-\delta) d \\
& \leq \frac{\delta+y_{1}^{*}}{1+\delta}-(1-\delta) u_{2}\left(a^{1}\right)-\frac{\delta}{1+\delta}\left(1-u_{1}\left(a^{*}\right)+\delta u_{2}\left(a^{*}\right)\right)
\end{aligned}
$$

Therefore, player 2 will not deviate from $a^{1}$.

Player 2 will also not deviate from $f_{2}\left(h_{2}(t)\right)$ : If player 1 were to deviate from $f_{1}\left(h_{1}(t)\right)$, player 2's payoff from rejecting will be $\frac{\delta+y_{i}^{*}}{1+\delta}$. Therefore, player 2 will accept the proposal only if player 1 proposes less than $\frac{1-y_{1}^{*}}{1+\delta}$. On the other hand, if player 1 follows $f_{1}\left(h_{1}(t)\right.$ ), player 2's payoff from rejecting will be

$$
(1-\delta) u_{2}\left(a^{*}\right)+\frac{\delta}{1+\delta}\left(1-u_{1}\left(a^{*}\right)+\delta u_{2}\left(a^{*}\right)\right)=\frac{1}{1+\delta}\left[\delta-\delta u_{1}\left(a^{*}\right)+u_{2}\left(a^{*}\right)\right.
$$

which is less than $\frac{\delta+y_{i}^{*}}{1+\delta}$. Therefore, player 2 will not deviate from $f_{2}\left(h_{2}(t)\right)$.

Finally, player 1 will not deviate from $f_{1}\left(h_{1}(t)\right)$ : If player 1 were to make a higher proposal player 2 will reject and propose $\frac{1-\delta}{\delta} u_{2}\left(a^{1}\right)+\frac{1}{\delta(1+\delta)}\left(\delta^{2}-y_{1}^{*}\right)$ in period $(t+2)$. Since $x_{1}^{*}+y_{1}^{*} \leq 1$ by A2,

$$
\begin{aligned}
(1-\delta) u_{1}\left(a^{1}\right)+(1-\delta) u_{2}\left(a^{1}\right)+\frac{\delta^{2}-y_{1}^{*}}{1+\delta} & =(1-\delta)\left(x_{1}^{*}+y_{1}^{*}\right)+\frac{\delta^{2}-y_{1}^{*}}{1+\delta} \\
\leq(1-\delta)+\frac{\delta^{2}-y_{1}^{*}}{1+\delta} & =\frac{1-y_{1}^{*}}{1+\delta}
\end{aligned}
$$

Therefore, player 1 will not deviate from $f_{1}\left(h_{1}(t)\right)$. This concludes the checks for an odd period.

In an even period $(t+1)$, when either $f\left(h_{3}(t-1)\right)=a^{*}$ or $a_{1}^{t}=f_{1}\left(h_{3}(t-1)\right), a_{2}^{t} \neq$ $f_{2}\left(h_{3}(t-1)\right)$ or $b^{t+1}<f_{2}\left(h_{1}(t)\right)$, Theorem 1 implies that the induced strategy forms a perfect equilibrium in such a subgame, because the disagreement payoff in every period thereafter is the Nash equilibrium payoff $u\left(a^{*}\right)$. Otherwise, if player 2 has not deviated last, there are two cases that have to be considered. 
Case 1: $a_{1}^{t} \neq a_{1}^{1}$ and $a_{2}^{t}=a_{2}^{1}$

Player 1 deviated in the stage game in period $t$. Player 1 will not deviate from $m^{1}$, because $m^{1}$ is his minimax strategy. If player 2 deviates from $m^{1}$, the disagreement payoff will be $u\left(a^{*}\right)$ in every period thereafter, and player 1 will propose $\frac{1}{1+\delta}\left(\delta-\delta u_{1}\left(a^{*}\right)+u_{2}\left(a^{*}\right)\right)$ to player 2 instead of $\frac{\delta+y_{i}^{*}}{1+\delta}$. Inequality (21) and the definition of $d$ imply that

$$
(1-\delta) \max _{a_{2}^{\prime} \in A_{2}} u_{2}\left(m_{1}^{1}, a_{2}^{\prime}\right)+\delta \frac{\delta-\delta u_{1}\left(a^{*}\right)+u_{2}\left(a^{*}\right)}{1+\delta} \leq(1-\delta) u_{2}\left(m^{1}\right)+\delta \frac{\delta+y_{1}^{*}}{1+\delta}
$$

Therefore, player 2 will not deviate from $m^{1}$.

Player 1 will not deviate from $f_{1}\left(h_{2}(t)\right)$ : If player 2 follows his strategy, player 1's payoff from rejecting will be $\frac{\delta}{1+\delta}\left(1-y_{1}^{*}\right)$. So, player 1 will accept. If player 2 deviates, player 1's payoff from rejection will be $\frac{1}{(1+\delta)}\left[\delta+u_{1}\left(a^{*}\right)-\delta u_{2}\left(a^{*}\right)\right]$, which is more than $\frac{\delta}{1+\delta}\left(1-y_{1}^{*}\right)$. Player 1 will therefore not deviate from $f_{1}\left(h_{2}(t)\right)$.

Player 2 will not deviate from $f_{2}\left(h_{1}(t)\right)$ either: If player 2 were to demand more, player 1 will reject and propose $\frac{1}{1+\delta}\left(\delta-\delta u_{1}\left(a^{*}\right)+u_{2}\left(a^{*}\right)\right)$ to player 2 in period $(t+2)$. Since $\delta u_{2}\left(a^{*}\right)-u_{1}\left(a^{*}\right)<u_{2}\left(a^{*}\right)-u_{1}\left(a^{*}\right)<y_{1}^{*}$,

$$
(1-\delta) u_{2}\left(a^{*}\right)+\delta \frac{\delta-\delta u_{1}\left(a^{*}\right)+u_{2}\left(a^{*}\right)}{1+\delta}<\frac{1-u_{1}\left(a^{*}\right)+\delta u_{2}\left(a^{*}\right)}{1+\delta}<\frac{1+y_{1}^{*}}{1+\delta}
$$

Therefore, player 2 will not deviate from $f_{2}\left(h_{1}(t)\right)$.

Case 2: $a^{t}=a^{1}$

For the same reasons as in Case 1, players will not deviate from $f\left(h_{3}(t)\right)=m^{1}$.

If player 2 follows his strategy, player 1 will accept, since his payoff from rejecting is equal to $\frac{\delta}{1+\delta}\left(1-y_{1}^{*}\right)$ which is less than $\frac{1-\delta}{\delta} u_{2}\left(a^{1}\right)+\frac{1}{\delta(1+\delta)}\left(\delta^{2}-y_{1}^{*}\right)$ due to

$$
\begin{aligned}
y_{1}^{*} \leq u_{2}\left(a^{1}\right) & \Rightarrow\left(1-\delta^{2}\right) y_{1}^{*} \leq\left(1-\delta^{2}\right) u_{2}\left(a^{1}\right) \\
& \Rightarrow \delta^{2}\left(1-y_{1}^{*}\right) \leq\left(1-\delta^{2}\right) u_{2}\left(a^{1}\right)+\delta^{2}-y_{1}^{*} \\
& \Rightarrow \frac{\delta}{1+\delta}\left(1-y_{1}^{*}\right) \leq \frac{1-\delta}{\delta} u_{2}\left(a^{1}\right)+\frac{1}{\delta(1+\delta)}\left(\delta^{2}-y_{1}^{*}\right)
\end{aligned}
$$


On the other hand, if player 2 were to demand more, player 1's payoff from rejecting is equal to

$$
(1-\delta) u_{1}\left(a^{*}\right)+\frac{\delta}{1+\delta}\left(1+\delta u_{1}\left(a^{*}\right)-u_{2}\left(a^{*}\right)\right)=\frac{1}{1+\delta}\left(\delta+u_{1}\left(a^{*}\right)-\delta u_{2}\left(a^{*}\right)\right)
$$

which is greater than or equal to $\frac{1-\delta}{\delta} u_{2}\left(a^{1}\right)+\frac{\delta^{2}-y_{i}^{*}}{\delta(1+\delta)}$ due to (22). Therefore, player 1 will not deviate from $f_{1}\left(h_{2}(t)\right)$.

Player 2 will follow $f_{2}\left(h_{1}(t)\right)$ : If player 2 were to demand more, player 1 will reject and propose $\frac{\delta}{1+\delta}\left(\delta-\delta u_{1}\left(a^{*}\right)+u_{2}\left(a^{*}\right)\right)$ to player 2 in period $(t+2)$. Player 2 's payoff then would be

$$
\begin{aligned}
(1-\delta) u_{2}\left(a^{*}\right)+\frac{\delta}{1+\delta}\left(\delta-\delta u_{1}\left(a^{*}\right)+u_{2}\left(a^{*}\right)\right) & <\frac{1}{1+\delta}\left(1-u_{1}\left(a^{*}\right)+\delta u_{2}\left(a^{*}\right)\right) \\
<\frac{\delta+y_{1}^{*}}{\delta(1+\delta)}-\frac{1-\delta}{\delta} u_{2}\left(a^{1}\right) & =1-\frac{1-\delta}{\delta} u_{2}\left(a^{1}\right)-\frac{\delta^{2}-y_{1}^{*}}{\delta(1+\delta)}
\end{aligned}
$$

Therefore, player 2 will not deviate from $f_{2}\left(h_{1}(t)\right)$.

It has been shown thät the strategy profile $f$ constitutes a subgame perfect equilibrium for the negotiation game $N G_{1}(\delta)$. The equilibrium outcome is that player 1 's proposal is accepted by player 2 in the first period, yielding average payoffs of $\left(\frac{1}{1+\delta}\left(1-y_{1}^{*}\right), \frac{1}{1+\delta}\left(\delta+y_{1}^{*}\right)\right)$.

Finally, consider the one period history $h_{1}(1)=1 \oplus\left(a_{1}^{\prime}, a_{2}^{1}\right)$ where $a_{1}^{\prime} \neq a_{1}^{1} .\left.f\right|_{h_{1}(1)}$ is a perfect equilibrium of $\left.N G_{1}(\delta)\right|_{h_{1}(1)}$ which is $N G_{2}(\delta)$, and the equilibrium outcome is that player 2's proposal is accepted by player 1 in the first period, yielding average payoffs of $\left(\frac{\delta}{1+\delta}\left(1-y_{1}^{*}\right), \frac{1}{1+\delta}\left(1+\delta y_{1}^{*}\right)\right)$. This proves the theorem for the game $N G_{2}(\delta)$.

Q.E.D.

Proof to Theorem 5, Section 3.3 The theorem is proven for $N G_{1}(\delta)$ only, but the arguments can easily be adapted to prove the theorem for $N G_{2}(\delta)$. Let $a^{*}$ be a Nash equilibrium of $G$. Since $\left(v_{1}, v_{2}\right)>\left(\underline{v}_{1}, \underline{v_{2}}\right), \exists \epsilon_{0}=\min \left\{v_{1}-\underline{v_{1}}, v_{2}-\underline{v_{2}}\right\} / 2>0$. According to the results in section $3.2, \exists \underline{\delta}$ such that, $\forall \delta \in(\underline{\delta}, 1)$, the game $N G_{j}(\delta)$ has an optimal 
punishment equilibrium for player $i$ with strategy $f^{i j}$, and

$$
\begin{aligned}
& \underline{v_{1}}+\epsilon_{0} \geq \max \left\{\frac{1-y_{1}^{*}}{1+\delta} ;(1-\delta) u_{1}\left(a^{*}\right)+\delta \frac{1-y_{1}^{*}}{1+\delta} ; 1-(1-\delta) u_{2}\left(a^{*}\right)-\delta \frac{\delta+y_{1}^{*}}{1+\delta}\right\} \\
& \underline{v_{2}}+\epsilon_{0} \geq \max \left\{\frac{1-x_{2}^{*}}{1+\delta} ;(1-\delta) u_{2}\left(a^{*}\right)+\delta \frac{1-x_{2}^{*}}{1+\delta} ; 1-(1-\delta) u_{1}\left(a^{*}\right)-\delta \frac{\delta+x_{2}^{*}}{1+\delta}\right\} \\
& \frac{1-\delta}{\delta} d \leq \epsilon_{0} \leq v_{i}-\left(\underline{v_{i}}+\epsilon_{0}\right) \text { for } i=1,2
\end{aligned}
$$

$\forall \delta \in(\underline{\delta}, 1), \exists \hat{a} \in A, \hat{b} \in[0,1]$ and a positive integer $T$ (which may or may not be finite), such that

$$
\left(v_{1}, v_{2}\right)=\left(1-\delta^{T}\right) u(\hat{a})+\delta^{T}(\hat{b}, 1-\hat{b}) \text { and }(\hat{b}, 1-\hat{b})>v>u(\hat{a})
$$

Consider the outcome path $\pi(T)=\hat{b}(T) \oplus \hat{a}(T-1) \oplus\{Y\}$ of $N G_{1}(\delta)$, where

$$
\hat{a}(T-1)=\left\{\hat{a}^{t}\right\}_{t=1}^{T-1} \in A^{T-1} \text { and } \hat{b}(T)=(1,0,1,0, \ldots, \hat{b})
$$

Inequality (26) implies that players' average payoffs from the outcome path $\pi(T)$ are $\left(v_{1}, v_{2}\right)$. Let $I D(\cdot)$ be the indicator function for the outcome path $\pi(T)$ as defined. Decompose the type $k t$-period history $h_{k}(t) \in H_{k}$ as $h_{k}(t)=h_{1}(s) \oplus h_{k}(t-s)$, for $k=1,2,3$ and $s \leq t$.

Consider the given strategy profile $f=\left(f_{1}, f_{2}\right)$. It remains to verify that $f$ constitutes a SPE for $N G_{1}(\delta)$.

$\forall h_{1}(t) \in H_{1}$, if $I D\left(h_{1}(t)\right) \neq 0,\left.f\right|_{h_{1}(t)}$ is one of the four strategy profiles $f^{11}, f^{12}, f^{21}$ or $f^{22}$, which are subgame perfect due to Theorems 3 and 4. Therefore, the strategy profiles under consideration are subgame perfect if $I D\left(h_{1}(t)\right) \neq 0$. It remains to verify the strategy profile along the proposed path $\pi(T)$, i.e. for $I D\left(h_{1}(t)\right)=0$ and $(t+1) \leq T$. Due to symmetry, only an odd period $(t+1)$ before period $T$ needs to be considered.

$\forall h_{1}(t) \in H_{1}$ such that $I D\left(h_{1}(t)\right)=0$, player 1 will follow the strategy to propose 1 in period $(t+1)<T$ and $\hat{b}$ in period $T$. If player 1 follows this strategy his average payoff will be, by (26) above,

$$
\left(1-\delta^{T-t}\right) u(\hat{a})+\delta^{T-t} \hat{b} \geq v_{1}
$$


However, if player 1 deviates, according to the strategy and (23), his average payoff will be either

$$
\begin{aligned}
& (1-\delta) u_{1}\left(a^{*}\right)+\delta \frac{\delta\left(1-y_{1}^{*}\right)}{1+\delta}<(1-\delta) u_{1}\left(a^{*}\right)+\delta \frac{1-y_{1}^{*}}{1+\delta}<v_{1} \\
& \text { or } \quad 1-(1-\delta) u_{2}\left(a^{*}\right)-\frac{\delta}{1+\delta}\left(\delta+y_{1}^{*}\right) \leq \underline{v_{1}}+\epsilon_{0}<v_{1}
\end{aligned}
$$

Therefore, player 1 will not deviate from $f_{1}\left(h_{1}(t)\right)$.

$\forall h_{2}(t) \in H_{2}$. If $I D\left(h_{2}(t)\right)=(1, t+1)$, player 1 has deviated from $f_{1}\left(h_{1}(t)\right)$ in period $(t+1)$. Player 2's payoff from rejecting is

$$
(1-\delta) u_{2}\left(a^{*}\right)+\delta \frac{\delta+y_{1}^{*}}{1+\delta}
$$

Therefore, player 2 will accept a proposal only if his share is not less than (27) before period $T$. In period $T,(23)$ and (26) imply that $1-\hat{b}$ is less than (27), so player 2 will reject if player 1 demands more than $\hat{b}$ in period $T$. If $I D\left(h_{2}(t)\right)=0$, player 2 will reject in period $(t+1)<T$, since his payoff from accepting is 0 which is certainly less than that from rejecting. In period $T$, player 2 will accept the proposal if $I D\left(h_{2}(T-1)\right)=0$. Due to (24) and (26), his payoff from rejecting satisfies

$$
(1-\delta) u_{2}\left(a^{*}\right)+\delta \frac{1-x_{2}^{*}}{1+\delta}<v_{2}
$$

which is less than $1-\hat{b}$. Therefore, player 2 will not deviate from $f_{2}\left(h_{2}(t)\right)$.

$\forall h_{3}(t) \in H_{3}$. If $I D\left(h_{3}(t)\right)=0, f\left(h_{3}(t)\right)=\hat{a}$. Neither players will deviate from $\hat{a}$, since

$$
\begin{aligned}
\frac{1-\delta}{\delta}\left[\max _{a_{1}^{\prime} \in A_{1}} u_{1}\left(a_{1}^{\prime}, \hat{a}_{2}\right)-u_{1}(\hat{a})\right] & \leq \frac{1-\delta}{\delta} d \leq \epsilon_{0} \leq v_{1}-\left(\underline{v_{1}}+\epsilon_{0}\right) \\
& \leq\left(1-\delta^{T-t-1}\right) u_{1}(\hat{a})+\delta^{T-t-1} \hat{b}-\frac{1-y_{1}^{*}}{1+\delta} \\
\text { and } & \leq \frac{1-\delta}{\delta} d \leq \epsilon_{0} \leq v_{2}-\left(\underline{v_{2}}+\epsilon_{0}\right) \\
& \leq\left(1-\delta^{T-t-1}\right) u_{2}(\hat{a})+\delta^{T-t-1} \hat{b}-\frac{1-x_{2}^{*}}{1+\delta}
\end{aligned}
$$


due to (23), (25) and (26). If $I D\left(h_{3}(t)\right)=(i, t+1), i=1,2, f\left(h_{3}(t)\right)=a^{*}$. Since $a^{*}$ is a Nash equilibrium in the stage game and the continuation payoff is history independent, no player can increase his payoffs in period $(t+1)$ or thereafter by deviating from $a^{*}$ individually. Therefore, players will not deviate from $f\left(h_{3}(t)\right)$.

$\left(v_{1}, v_{2}\right)$ is, therefore, supported by the strategy profile $f$ as a subgame perfect equilibrium payoff from the outcome path $\pi(T)$ in the negotiation game $N G_{1}(\delta)$.

Q.E.D. 


\section{References}

[1] Abreu, Dilip: "Extremal Equilibria of Oligopolistic Supergames," Journal of Economic Theory, 39(1986), 191-225.

[2] Abreu, Dilip: "On The Theory of Infinitely Repeated Games with Discounting," Econometrica, 56(1988), 383-396.

[3] Abreu, Dilip, David Pearce, and Ennio Stacchetti: "Toward a Theory of Discounted Repeated Games with Imperfect Monitoring," Econometrica, 58(1990), 1041-1063.

[4] Admati, A.R., and M. Perry: "Strategic Delay in Bargaining," Review of Economic Studies, LIV(1987), 345-364.

[5] Ausubel, Lawrence M., and Raymond J. Deneckere: "A Direct Mechanism Characterization of Sequential Bargaining with One-Sided Incomplete Information," Journal of Economic Theory, 48(1989), 18-46.

[6] Ausubel, Lawrence M., and Raymond J. Deneckere: "Reputation in Bargaining and Durable Goods Monopoly," Econometrica, 57(1989), 511-532.

[7] Benoit J.-P., and V. Krishna: "Finitely Repeated Games," Econometrica, 53(1985), 905-922.

[8] Binmore, K.: "Perfect Equilibrium in Bargaining Models," in "Bargaining: Vol II", ed. P. Dasgupta and K. Binmore, Basil Blackwell, 1987.

[9] Chatterjee, Kalyan, and Larry Samuelson: "Bargaining with Two-Sided Incomplete Information: An Infinite Horizon Model with Alternating Offers," Review of Economic Studies, LIV(1987), 175-192.

[10] van Damme, E.: "Renegotiation-Proof Equilibria in Repeated Prisoners' Dilemma," Journal of Economic Theory, 47(1989), 206-217. 
[11] Farrell, J. and E. Maskin: "Renegotiation in Repeated Games," Harvard Institute of Economic Research Discussion Paper No. 1335, Harvard University, 1987.

[12] Fernandez, Raquel, and Jacob Glazer: "Striking For A Bargain Between Two Completely Informed Agents," American Economic Review, 81(1991), 240-252.

[13] Fudenberg, D.: "Nash and Perfect Equilibria of Discounted Repeated Games," Journal of Economic Theory, 51(1990), 194-206.

[14] Fudenberg, D., and E.Maskin: "The Folk Theorem in Repeated Games with Discounting or with Incomplete Information," Econometrica, 54(1986), 533-554.

[15] Gul, F., and H. Sonnenschein: "On Delay in Bargaining with One-Sided Uncertainty," Econometrica, 56(1988), 601-612.

[16] Haller, Hans, and Steinar Holden: "A Letter to the Editor on Wage Bargaining," Journal of Economic Theory, 52(1990), 232-236.

[17] Kreps, D., P. Milgrom, J. Roberts, and R. Wilson: "Rational Cooperation in the Finitely-Repeated Prisoners' Dilemma," Journal of Economic Theory, 27(1982), 245252.

[18] Okada, Akira: "A Two-Person Repeated Bargaining Game With Long-Term Contracts," The Center for Mathematical Studies in Economics and Management Science, Northwestern University, Discussion Paper No.706, 1986.

[19] Rubinstein, Ariel: "Perfect Equilibrium in a Bargaining Model," Econometrica, 50(1982), 97-109.

[20] Selten, R.: "Reexamination of the Perfectness Concept for Equilibrium Points in Extensive Games," International Journal of Game Theory, 4(1975), 25-55. 
[21] Shaked, A. and J. Sutton: "Involuntary Unemployment as a Perfect Equilibrium in a Bargaining Model," Econometrica, 52(1984), 1351-1364.

[22] Wilson, R.: "Game-theoretic Analyses of Trading Processes," in "Advances in Economic Theory" ed. T. Bewley, Cambridge University Press, 1987. 